\title{
Application of Graphene in Fiber-Reinforced Cementitious Composites: A Review
}

\author{
Songmei $\mathrm{Wu}^{1, *}$, Tanvir Qureshi ${ }^{2}$ (D) and Guorui Wang ${ }^{3, *(D)}$ \\ 1 Department of Textile and Garment, Anhui Vocational and Technical College, Hefei 230011, China \\ 2 Department of Geography and Environmental Management, University of the West of England, \\ Bristol BS16 1QY, UK; tanvir.qureshi@utoronto.ca \\ 3 Department of Mechanical and Industrial Engineering, University of Toronto, Toronto, ON M5S 3G8, Canada \\ * Correspondence: wusm@uta.edu.cn (S.W.); guorui.wang@utoronto.ca (G.W.)
}

check for updates

Citation: Wu, S.; Qureshi, T.; Wang,

G. Application of Graphene in

Fiber-Reinforced Cementitious

Composites: A Review. Energies 2021,

14, 4614. https://doi.org/10.3390/

en14154614

Academic Editor: Carlos

Miguel Costa

Received: 30 June 2021

Accepted: 28 July 2021

Published: 30 July 2021

Publisher's Note: MDPI stays neutral with regard to jurisdictional claims in published maps and institutional affiliations.

Copyright: (c) 2021 by the authors. Licensee MDPI, Basel, Switzerland. This article is an open access article distributed under the terms and conditions of the Creative Commons Attribution (CC BY) license (https:// creativecommons.org/licenses/by/ $4.0 /)$.

\begin{abstract}
Graphene with fascinating properties has been deemed as an excellent reinforcement for cementitious composites, enabling construction materials to be smarter, stronger, and more durable. However, some challenges such as dispersion issues and high costs, hinder the direct incorporation of graphene-based reinforcement fillers into cementitious composites for industrial production. The combination of graphene with conventional fibers to reinforce cement hence appears as a more promising pathway especially towards the commercialization of graphene for cementitious materials. In this review paper, a critical and synthetical overview on recent research findings of the implementation of graphene in fiber-reinforced cementitious composites was conducted. The preparation and characterization methods of hybrid graphene-fiber fillers are first introduced. Mechanical reinforcing mechanisms are subsequently summarized, highlighting the main contribution of nucleation effect, filling effect, interfacial bonding effect, and toughening effect. The review further presents in detail the enhancements of multifunctional properties of graphene-fiber reinforced cementitious composites, involving the interfacial properties, mechanical properties, durability, electrical conductivity, and electromagnetic interference shielding. The main challenges and future prospects are finally discussed to provide constructive ideas and guidance to assist with relevant studies in future.
\end{abstract}

Keywords: graphene; graphene oxide; reduced graphene oxide; fiber-reinforced cementitious composites; interface; mechanical properties; electrical properties; durability; electromagnetic interference shielding

\section{Introduction}

With the rapid development of economies and infrastructure construction, cementbased materials (e.g., paste, mortar, and concrete) have become one of the most widely used building materials due to their wide availability, high durability, and relative low cost [1,2]. However, the intrinsically low toughness and tensile strength of cement have been found to be main causes of infrastructure failures and deterioration issues [3]. To this end, substantial efforts have been directed towards improving the mechanical properties of the cementitious materials by incorporating the reinforcing fibers into composites. Representative examples include steel fibers [4,5], carbon fibers [6,7], and polymeric fibers [8,9], which aid to arrest crack opening and endow the fiber-reinforced cementitious composites (FRCC) with increased tensile strength and toughness.

Classic views of conventional fiber-reinforced composites suggest that the mechanical reinforcing effect greatly depends on the interfacial bonding properties between the filler and surrounding matrix [10]. Due to the chemical inertness of fiber surfaces, the load transfer across the interface within FRCC is always limited by the weak interfacial adhesion. Specifically, pullout failures are frequently observed on the fracture surface for those fibers with low aspect ratio [11,12]. The inertia of fibers further makes them easily aggregate in the cement matrix, leading to the poor dispersion that is detrimental to the mechanical 
properties of FRCC. In addition, the inclusion of microfibers tends to induce extra air voids in concrete during the casting process and results in a reduction in compressive strength $[13,14]$. In this context, the advancements of nanotechnology and nanomaterials have brought tremendous opportunities to enhance the overall performance of concrete and FRCC.

Amongst various nanomaterials, graphene and graphene-derived materials-such as graphene oxide (GO) and reduced graphene oxide (rGO) - stand out as the 2D nanoreinforcing fillers in cementitious composites, not only due to their superior mechanical properties but also their considerable functional versatility [15-19]. Graphene, being the thinnest possible material $(\sim 0.34 \mathrm{~nm})$, is also the strongest discovered material to date, showing a fracture strength up to $100 \mathrm{GPa}$ and a fatigue life of more than a billion cycles [20-22]. Nevertheless, main concerns regarding dispersion issues also exist for graphene, especially considering its ultrahigh specific surface area. By comparison, GO provides a higher dispersibility and compatibility in cement with the presence of various oxygen-containing functional groups, like hydroxyl, epoxide, carboxyl, and carbonyl groups $[23,24]$. These functional groups combined with high surface area of GO further facilitate the nucleation of calcium silicate hydrate (C-S-H) and allow for the formation of chemical bonding networks to enhance the mechanical strength of GO-reinforced cementitious composites (GRCC) [25-27]. Moreover, the nanoscale 2D size allows GO to fill in the tiny cracks and voids between hydration products of cement, thus decreasing the porosity and improving the compactness [28]. Upon mechanical damage, GO sheets can provide toughening mechanism by triggering crack deflection, branching, and bridging, leading to an increased failure tolerance of GRCC $[29,30]$. One limitation for GO reinforcement is that the extensive defects account for the degradation of the mechanical properties. The fracture strength was found to reduce to around $30 \mathrm{GPa}$ at $20 \%$ hydroxyl functionalization [31]. To this end, the oxygen-containing functional groups of GO can be reduced to generate rGO, which restores the mechanical properties of pristine graphene while maintaining the hydrophilicity to be dispersive in cement.

Despite considerable progress achieved in the fundamental research of graphenebased cementitious composites, it remains a great challenge for the "lab-to-fab" transition. The biggest difficulty lies in graphene production with controllable quality at low cost on an industrial scale. Firstly, the quality control of graphene has long been a roadblock for its industrialization. In reality, multilayer graphene nanoplatelets (GNP) are most commonly used in practical applications, as GNP can be easily produced from graphite. However, a survey of commercially available graphene products from 60 producers revealed a statistic distribution of lateral size, thickness, and defects [32,33]. Most companies are actually producing "flake graphene", i.e., graphite microplatelets with poor qualities. Similarly, the run-to-run variation of size and functionalized degree for GO products also gives rise to different dispersibility, interfacial bonding, and cement hydration rates, hence influencing the eventual mechanical durability of GRCC. Besides, the cost-effectiveness and scalability raise additional concerns for the realistic application of graphene-based materials in the construction industry $[34,35]$. Therefore, it is of paramount importance to find a more efficient and cost-effective way to exploit graphene-based materials as reinforcements in cement materials. The balance between the working performance and industrial production is urgently required for the practical applications of advanced cementitious composite in infrastructure construction.

In this context, the combination of conventional fibers and graphene-based materials is likely to pave a promising pathway for the industrial manufacturing of high-performance smart cementitious composites. However, the study of hybrid graphene-fiber reinforced cementitious composites is still in the nascent stage. Limited attention has been devoted to understanding the microstructures, interfaces, and mechanical properties of graphene-fiber reinforced cementitious composites. More importantly, critical issues regarding the mix design and production procedure of hybrid reinforcements as well as cementitious composites need to be addressed. In the current study, recent research progress on the hybrid 
graphene-fiber reinforced cementitious composites is reviewed in detail. The chronological order of this review gives the reader a clear picture of the aspects of preparation methods, mechanical reinforcing mechanisms, as well as comprehensive enhancement in multi-functional properties of graphene-fiber reinforced cementitious composites. Special emphasis is placed on interfacial properties, mechanical properties, durability performance, electrical properties, and electromagnetic interference (EMI) shielding performance. The review aims to provide a guideline for the potent design of smart cementitious composites for infrastructure application as well as the scope of future research.

\section{Preparation of Hybrid Graphene-Fiber Reinforced Cementitious Composites}

Direct mixing of graphene is the most straightforward and commonly used preparation method for the hybrid graphene-fiber reinforced cementitious composite. First, GO is typically synthesized from the oxidation of graphite followed by purification and exfoliation process. Ultrasonic preprocessing is required to ensure uniform dispersion of GO in water. To increase the dispersibility of GO, polycarboxylic-based superplasticizer or methyl cellulose is used as a primary dispersant dissolved in water [36,37]. Meanwhile, the fibers are mixed with cement, sand, and binder in a mortar mixer at low speed. Then, the sonicated GO dispersion can be added in the mixture and continuously stirred. The water/cement ratio of mixtures specimen is usually kept within the range of $0.2-0.5$, as shown in Table 1. The mixtures are finally casted into steel molds and vibrated for densification after each casting. The surface of the castings is smoothed with a scraper and covered with preservative film to avoid water evaporation. Afterwards, specimens are demolded after $24 \mathrm{~h}$ initial hardening and then placed into a curing room $\left(20^{\circ} \mathrm{C} / \mathrm{RH} 95 \%\right)$ until testing.

Table 1. Preparation and characterization of hybrid graphene-fiber fillers and reinforced cementitious composites.

\begin{tabular}{|c|c|c|c|c|}
\hline Material & Amount & Preparation & Characterization & Reference \\
\hline GO/PVA fiber + OPC & $\begin{array}{l}\text {-Volume fraction of } 0.5 \% \\
\text {-GO/fiber mass ratio } \leq 0.15 \% \\
\text {-w/c } \sim 0.45 \\
\text {-s/c } 1.5 \\
\text {-SP 0.2 wt. } \%\end{array}$ & Dip coating + mixing & SEM, FTIR, Raman, AFM & [36] \\
\hline $\mathrm{GO} / \mathrm{CF}+\mathrm{OPC}$ & $\begin{array}{l}\text {-Mass content of } 0.1-0.4 \% \\
-w / c \sim 0.48\end{array}$ & $\begin{array}{l}\text { Electrophoretic deposition }+ \\
\text { mixing }\end{array}$ & SEM, FTIR, AFM & [37] \\
\hline $\mathrm{GO} / \mathrm{CF}+\mathrm{OPC}$ & $\begin{array}{l}\text {-Volume fraction of } 1.0 \% \\
\text {-w/c } 0.38 \\
\text {-s/c } 1.0 \\
\text {-SP } \sim 0.047 \text { wt. } \%\end{array}$ & $\begin{array}{l}\text { Modified electrophoretic } \\
\text { deposition + mixing }\end{array}$ & $\begin{array}{l}\text { XPS, Raman, SEM, 3D Surface } \\
\text { Metrology }\end{array}$ & [38] \\
\hline rGO/PVA fiber + OPC & $\begin{array}{l}\text {-Volume fraction of } 2.0 \% \\
\text {-w/c } 0.45 \\
\text {-s/c } 1.0 \\
\text {-SP } \sim 0.2 \text { wt. } \%\end{array}$ & Dip coating + mixing & XPS, Raman, SEM & [39] \\
\hline $\mathrm{GO} / \mathrm{PE}$ fiber $+\mathrm{OPC}$ & $\begin{array}{l}\text {-Volume fraction of } 2.0 \% \\
\text {-GO } 0.008 \% \text { wt. } \% \\
\text {-w/c } 0.2\end{array}$ & Dip coating + mixing & SEM, FTIR & [40] \\
\hline $\mathrm{GO}+\mathrm{CF}+\mathrm{OPC}$ & $\begin{array}{l}-\mathrm{GO} \sim 0.04-1.0 \mathrm{wt} . \% \\
-\mathrm{CF} \sim 1 \mathrm{wt} . \% \\
-\mathrm{w} / \mathrm{c} \sim 0.37\end{array}$ & Direct mixing & SEM, TEM & [41] \\
\hline $\mathrm{GO} / \mathrm{CF}+\mathrm{OPC}$ & $\begin{array}{l}\text {-Mass content of } 0.1-0.6 \% \\
-w / c \sim 0.44\end{array}$ & Direct mixing & SEM, FTIR, XRD & [42] \\
\hline
\end{tabular}

Note: OPC: Ordinary Portland cement; w/c: water/cement weight ratio; s/c: sand/cement weight ratio; SP: superplasticizer.

The most effective way to combine graphene and fibers is surface coating. Representative approaches for coating GO on micro-fibers involve dip coating, spray coating, chemical vapor deposition (CVD), electrophoretic deposition (EPD) method, sol-gel processing, and so forth [43,44]. For example, Yao et al. [36] employed a three-step dip coating method (Figure 1a) to fabricate the GO-coated polyvinyl alcohol (PVA) fibers. As illustrated in Figure 1b, polydopamine (PDA) was first covered onto PVA fibers through self-polymerization and subsequently grafted with polyethylenimine (PEI). The positively charged amine groups introduced by PEI help drive negatively charged GO flakes to the 
fiber surface via electrostatic attraction to build the amide bonds. Finally, the prepared PEI/PDA/PVA fibers were soaked into the GO solution $(0.8 \mathrm{mg} / \mathrm{mL})$ for $1 \mathrm{~h}$ to achieve a robust coating. Alternatively, Chen et al. [37] adopted the EPD technique to introduce GO coating on carbon fibers (CF). Before coating, electrochemical corrosion method was first used to remove the commercial sizing on the $\mathrm{CF}$, in order to improve the interfacial adhesion. The electrolytic treatment system typically consists of a potentiostat/galvanostat analyzer with $\mathrm{CF}$ as the working electrode and a graphite cathode as the counter electrode, as shown in Figure 1c. Upon the immersion treatment of CF in GO solution (electrolytic solution, $1.5 \mathrm{mg} / \mathrm{mL}$ ) for $40 \mathrm{~min}$ under the voltage of $15 \mathrm{~V}$, the electrophoretic deposition was completed. Later, Lu et al. [38] developed a novel EPD system for the mass production of hybrid GO/CF fibers, as depicted in Figure 1d. Therein, a copper encapsulated plastic box was devised as the working electrode meanwhile containing a cluster of CF. Two holes were drilled on box and quantitative filter papers were then placed between the hole and copper paper, to allow the diffusion of GO electrolyte while avoiding the leakage of CF. Another copper plate was used as the counter electrode, kept $5 \mathrm{~cm}$ from the plastic container. The $\mathrm{pH}$ of the electrolytic solution was adjusted to 10.0 by adding sodium hydroxide into the GO solution. EPD process was finally conducted at $20 \mathrm{~V}$ for $1 \mathrm{~h}$ to coat GO on CF.

(a)

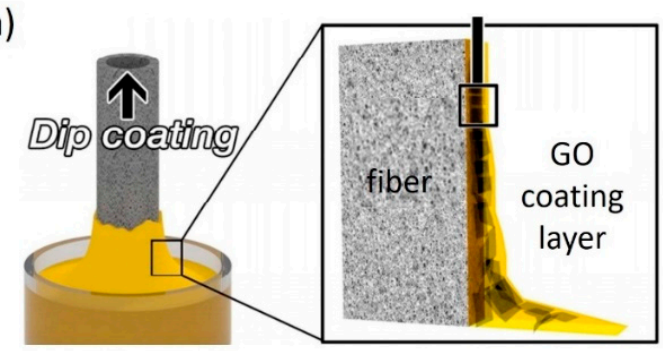

(c)

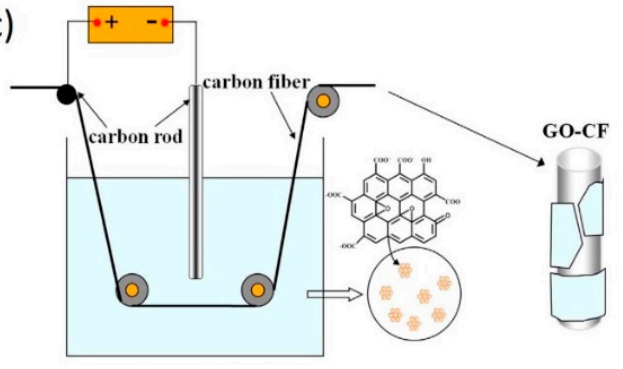

(b)

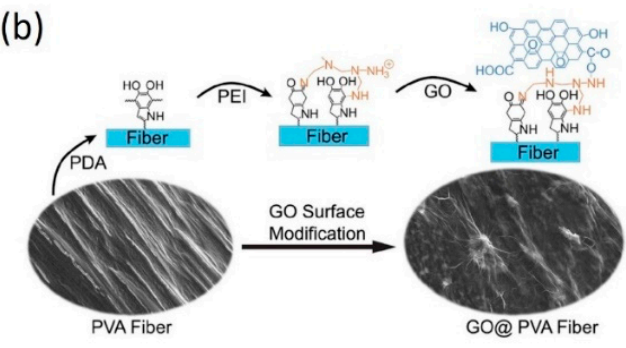

(d)

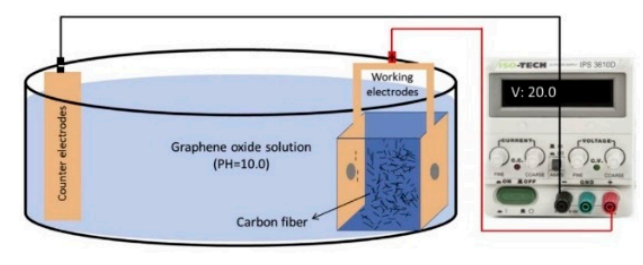

Figure 1. (a) Schematic representation of a typical dip-coating process [45] (Copyright permission Royal Society of Chemistry 2017); (b) Schematic illustration of the fabrication process of GO-coated PVA fibers [36] (Copyright permission Elsevier 2019); Schematic of (c) ordinary and (d) newly designed electrophoretic deposition system for the production of hybrid GO/CF fibers [37,38] (Copyright permission Elsevier 2015, 2018).

To confirm the successful coating and characterize the surface morphology and functional groups of $\mathrm{GO}$ on fibers, various characterization techniques are adopted including scanning electron microscopy (SEM) imaging, atomic force microscopy (AFM) imaging, X-ray photoelectron spectroscopy (XPS) analysis, Raman spectroscopy, and Fourier Transform Infrared Spectroscopy (FTIR) [36,37,39]. Figure 2a shows the typical SEM image of GO-coated PVA fibers, where a relatively smooth GO film with distributed wrinkles can be observed. In the magnified view, it is clear that GO flakes are folded and warped at the boundary. Based on AFM imaging, the thickness of GO coating can be measured by comparing the height difference between the uncoated fiber area and the flat coated area, giving a range of 50-500 nm. Due to the formation of wrinkles during the coating process, the surface roughness of hybrid GO/CF fiber appears higher than pristine CF ( $446 \mathrm{~nm}$ vs. $218 \mathrm{~nm}$ ), as shown in Figure 2b. Such a roughening can induce a larger interfacial frictional 
resistance and benefit the load transfer within the cementitious composites. In addition, from the contact angle measurement (Figure 2c), GO coating endows CF with a higher wettability, displaying a contact angle of $98.4^{\circ}$ compared to that of pristine one $\left(149.9^{\circ}\right)$. The hydrophilic surface feature will alleviate the dispersion issues and facilitate the cement hydration. Moreover, the Raman, FTIR, and XPS measurements all serve to identify the chemical composition and oxidized degree of GO coating present on fibers.

(a)
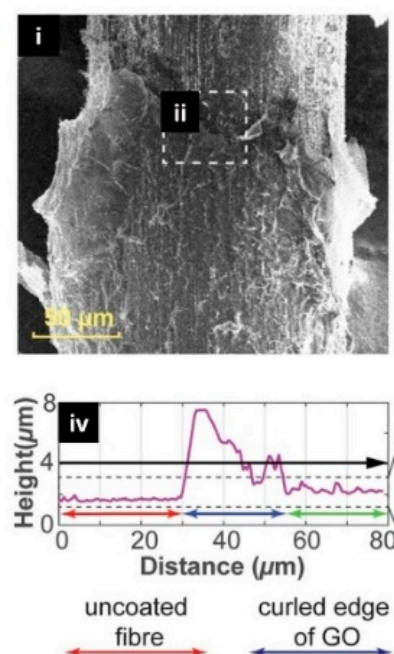
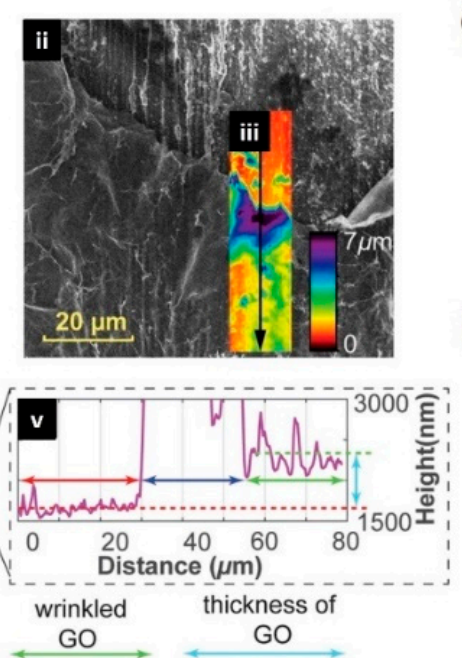

(b)

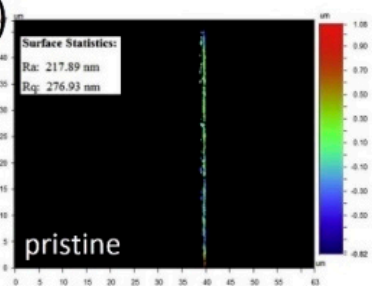

(c)

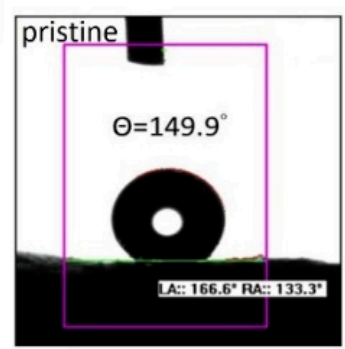

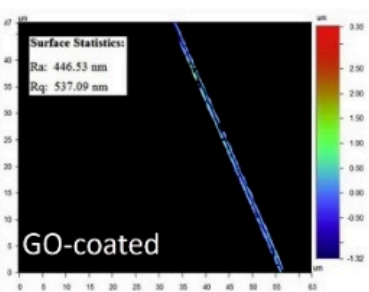

GO-coated

$\Theta=98.4^{\circ}$

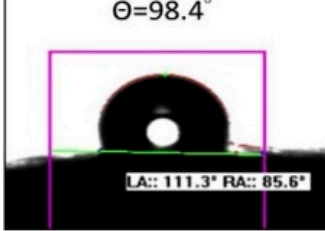

Figure 2. (a) Measurement of GO coating thickness on PVA fibers by AFM imaging of the boundary surface [36] (Copyright permission Elsevier 2019); (b) Surface roughness map and (c) contact angle measurement for pristine and GO-coated carbon fiber, respectively [38] (Copyright permission Elsevier 2018).

During the preparation of the cementitious composite, cement powder and sand are first dry mixed in a mortar mixer with a planetary rotating blade at low speed. Water is then added into the mixing batch until the desired flowability is achieved. Subsequently, graphene-coated fibers are added and dispersed in the cementitious mixture during the continuous mixing. Alternatively, fibers can also be dispersed in aqueous solutions prior to mixing with cement. In order to improve the dispersion of GO-coated fibers, GO solution can be used instead of the aqueous solution. Due to the ionization of the phenolic hydroxyl and carboxylic acid groups, electronegativity of the GO solution contributes to the better dispersion of GO-coated fibers in the GO solution. The larger electrostatic repulsion and steric stabilization between the GO result in the increased distance among the fibers [38].

\section{Mechanical Reinforcing Mechanisms in Hybrid Graphene-Fiber Reinforced Cementitious Composites \\ 3.1. Nucleation Effect}

Numerous studies $[1,25,27,46]$ have claimed that both graphene-based materials greatly impact the cement hydration process. Owing to the nanoscale size and ultrahigh specific surface area of graphene, plenty of nucleation sites are available in cement pastes, which facilitate the nucleation and growth of hydration products, as shown in Figure 3a [29]. In particular, Qureshi et al. [1] conducted a calorimetric study on cement paste composites that comprise three types of graphene-based materials (i.e., GNP, GO, and $\mathrm{rGO}$ ). Both GO and rGO display an enhancement in the heat rate of hydration during the early age hydration due to the presence of oxygen-containing functional groups. In contrast, the carbon-carbon $s p^{2}$-bonded networks of GNP can also serve as nucleation sites at the nanoscale during the cement hydration process even without surface functional groups, as evidenced by the increased cumulative heat of hydration compared to the control group. Similar acceleration of hydration kinetics was captured for Portland cement paste based on an isothermal calorimetry measurement [47]. Additionally, X-ray diffraction (XRD), 
FTIR spectroscopy, and XPS results further aid to interpret the role of oxygen-containing functional groups that promote the adsorption of water molecules and ions (e.g., $\mathrm{Ca}^{2+}$ ) for hydration acceleration of the cement [47-49]. It was reported that water adsorption could reduce the water-to-binder ratio within the interfacial zone surrounding graphene-based fillers as well as the whole cementitious composites during early hydration; in the later hydration stage, such adsorbed water would be released to favor the curing of cementitious composites and constrain the spontaneous shrinkage. Besides, the adsorption of ions may accelerate nucleation and increase calcium silicate hydrate $(\mathrm{C}-\mathrm{S}-\mathrm{H})$ gel aggregation, improving the compactness of cement [50].

\subsection{Filling Effect}

The hydrated cement paste matrix consists of calcium hydroxide, aluminate, unhydrated cement, and amorphous gel which also contains nano-, micro-, and meso-scale pores [51]. Specifically, the C-S-H gel is the major hydration product because of its abundance (50-70\% by volume) and high stiffness [52]. Despite the amorphous nature of C-S-H, well-organized structures composed of silicate chains held together by calcium oxide layers, are presented at the nanoscale [53]. Such a heterogeneous structural feature hence endows the cement paste with a porous nature. The porosity is a key parameter defining the mechanical behavior of cementitious composites, whereas inclusion of fibers may even exacerbate the porosity effect on the mechanical properties. In stark contrast to micro-fibers, nanosized graphene-based materials are capable of filling in the pores/voids at different scales within the hydrated cement matrix, as depicted in Figure 3b. Using a mercury intrusion porosimetry (MIP) test, Gong et al. [46] investigated the pore size distribution of the GO-reinforced cementitious composites. They found that the addition of GO effectively refined the microstructures of cement, leading to a $13.5 \%$ reduction of total porosity and a $27.7 \%$ decrease in capillary pore volume $(10 \mathrm{~nm}-10 \mu \mathrm{m})$, meanwhile increasing the number of C-S-H gel pore by $100 \%$. Since the number of C-S-H gel pore is proportional to the C-S-H gel concentration, the increased C-S-H gel pore volume implied a higher C-S-H gel content, which benefits the densification of hydrated cement matrix [54]. Analogously, by introducing GNP into the cement mortar, more than 30\% reduction was observed in the critical pore size, which improves the resistance of cement mortar to the permeability and corrosion [55]. The incorporation of rGO sheets in Portland cement was also found to be more efficient than the other nanomaterials (e.g., $\mathrm{Al}_{2} \mathrm{O}_{3}$ and $\mathrm{SiO}_{2}$ nanopowders) in refining the voids distribution in cement paste, decreasing the mass porosity and water sorptivity [56]. In addition, as discussed in Section 3.1, the graphene filler accelerated production of $\mathrm{C}-\mathrm{S}-\mathrm{H}$ gel further enhances the filling effect and decreases the porosity in the cementitious composite. However, of note is that excessively high filler content will have an adverse impact on the porosity refinement: (1) The overlap of graphene sheets may generate more pores between layers; (2) The increased viscosity of the composite may induce more pores during mixing process [57]; (3) The agglomeration easily results in large voids within the cement matrix, instead of filling in tiny pores [58]. Consequently, the mechanical properties such as hardness tend to be compromised.

\subsection{Interfacial Bonding Effect}

The oxygen-containing functional groups, including epoxide, hydroxyl, and carboxyl groups, can build strong interfacial bonds with $\mathrm{C}-\mathrm{S}-\mathrm{H}$ gel or calcium hydroxide in the cement [29]. As illustrated in Figure 3c, there are commonly two kinds of chemical interactions contributing to the interface adhesion: one is the ionic bonds between the calcium of $\mathrm{C}-\mathrm{S}-\mathrm{H}$ and the oxygen of functional groups attached on GO sheet, and the other is hydrogen bonds between water molecules in C-S-H and hydroxyl groups of GO [59]. Based on the molecular dynamics (MD) simulations, Wang et al. [60] further discovered that the hydroxyl groups exhibited a higher strength of interfacial bonding than carboxyl groups with $\mathrm{C}-\mathrm{S}-\mathrm{H}$, mainly attributed to formation of more chemical bonds with higher stability at $\mathrm{COOH} / \mathrm{C}-\mathrm{S}-\mathrm{H}$ interface. In addition, the presence of hydroxyl groups also 
increases the surface roughness of GO and activates the mechanical interlocking mechanism (Figure 3c), thus accounting for a stronger interfacial frictional resistance. In fact, Kai et al. [61] revealed the dominant role of mechanical interlocking in the interfacial shear strength between GO and C-S-H matrix by using pull-out simulations. Different from the pull-out test of conventional fibers, the interfacial resistance for nanoscale GO is determined not only by the friction but also the unbalanced adhesion forces near the crack surface [62]. As a result, they found that the interfacial shear strength of $\mathrm{CO} / \mathrm{C}-\mathrm{S}-\mathrm{H}$ interface can reach hundreds of MPa. Specifically, GO with epoxide and hydroxyl groups showed an interfacial shear strength that is respectively 6 and 9 times higher than that of GNP, which can only form van der Waals interactions with C-S-H. Obviously, the stronger interfacial bonding for $\mathrm{GO}$ would bring about more efficient load transfer across hydration phases and enhance the mechanical properties of cementitious composites. Despite the fact that the mechanical properties of GO sheet are lower than that of rGO and GNP sheet, the hydrophilic nature and stronger interfacial bonding behavior of GO makes it an ideal candidate for coating fiber to produce an efficient hybrid graphene-fiber reinforcing agent for the cementitious composite.

(a)

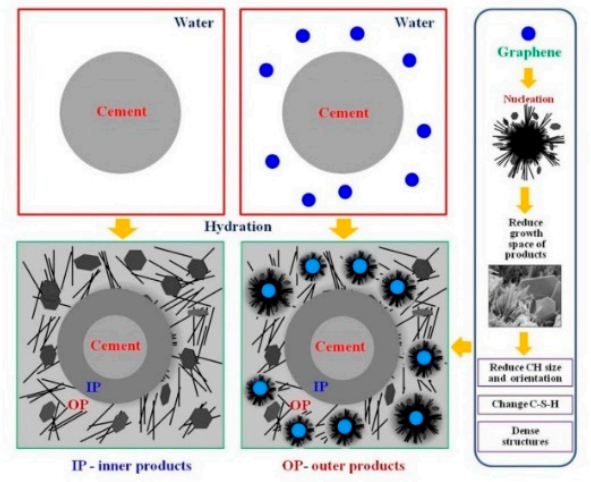

(c)

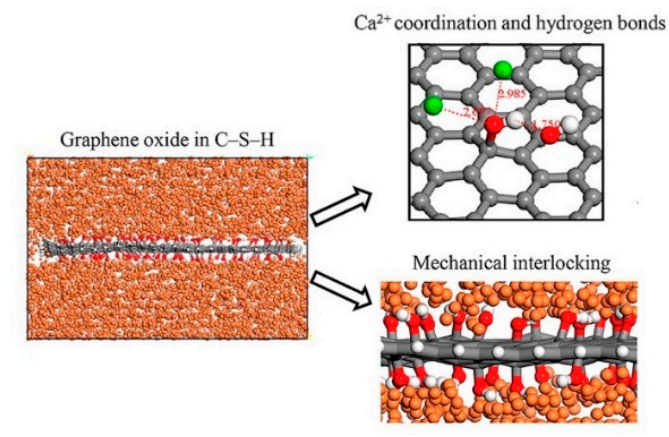

(b)

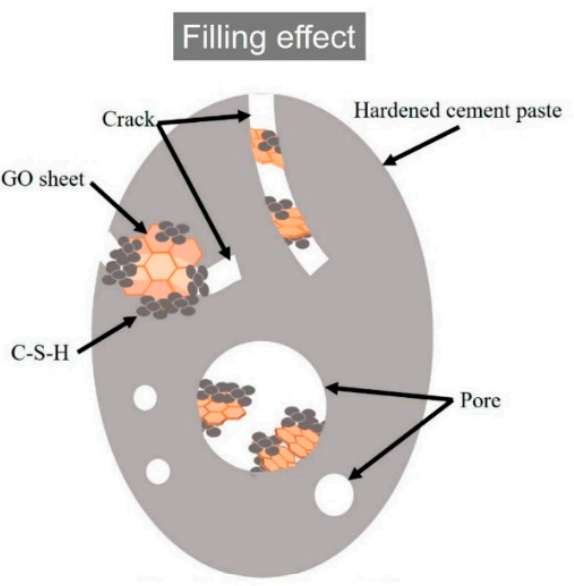

(d)
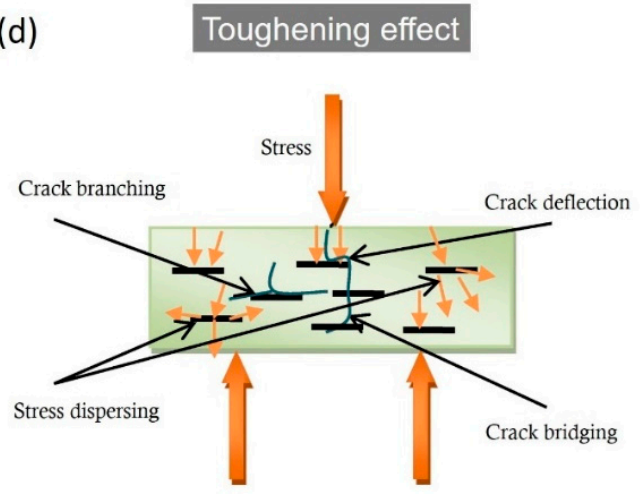

Figure 3. (a) Schematic diagram of graphene role in the hydration products growth around cement particles [65]; (b) Schematic illustration of reinforcement of hardened cement paste with well-dispersed GO [66]; (c) Simulation snapshots of chemical bonding and interlocking mechanism between GO and C-S-H structures [61] (Copyright permission Elsevier 2019); (d) Schematic of GNP/cement composites under bending load, showing various toughening mechanisms [67].

\subsection{Toughening Effect}

Adding graphene fillers in cementitious composite not only provides strengthening mechanisms but also serves as a toughening strategy due to the better control cracks across multiple length scales [63]. Generally, the toughening mechanisms of graphene-reinforced cementitious composites rest on the delayed initiation and hindered propagation of cracks 
due to the regulated hydration products and strong interfacial bonding. In detail, as shown in Figure 3d, upon the initiation of the first crack under three-point bending, it will propagate along the interface between the graphene and cement matrix when reaching the graphene flake surface, leading to crack branching or crack deflection. The crack path is thus increased to dissipate more energies. Furthermore, the crack bridging of graphene flakes over the crack sites can effectively absorb more energies. Direct evidence of graphene pull-out failure can also be observed in cementitious composite by SEM, where the interfacial sliding is also responsible for the toughening effect [64].

\section{Enhancement in Properties and Performance of Cementitious Composite by Hybrid Graphene-Fiber}

\subsection{Interfacial Properties}

The reinforcing effect of cementitious composite is originated from the load-bearing capability of fillers, depending on the efficiency of load transfer from cement matrix. Therefore, the mechanical reinforcement of FRCC is not only dictated by the intrinsic mechanical properties of fibers but more importantly, the bonding strength at the fiber/cement interface. However, for certain fibers (e.g., carbon fiber) with inert and hydrophobic surface, they are prone to cluster in and interact with the cement matrix by weak van der Waals forces, thus considerably suppressing the mechanical reinforcement to cementitious composites. To this end, in addition to chemical functionalization, coating the fiber with GO affords another effective strategy to enhance the interfacial interactions between the fiber and cement matrix.

As mentioned in Section 3.3, abundant oxygen-containing functional groups can form strong chemical bonding as well as mechanical interlocking with $\mathrm{C}-\mathrm{S}-\mathrm{H}$. This was directly evidenced by the SEM imaging of the fracture surface as shown in Figure 4a,b [38]. As a control group, pristine carbon fiber presents a smooth surface and an interfacial gap within the cement matrix, implying the occurrence of interfacial sliding due to the weak bonding. In contrast, a substantial amount of cement hydration products can be visible on the surface of GO-coated carbon fiber, which provide a higher interfacial bonding strength. Similar phenomena were also observed for other cementitious composites reinforced by, for example, rGO/CF, GO/PVA fiber, GO/polyethylene (PE) fiber [6,36,40]. Note that, compared with small GO flakes, large GO flakes are expected to achieve a full coverage of coating on fibers, hence performing better in acceleration of cement hydration and strengthening of interfacial bonds.
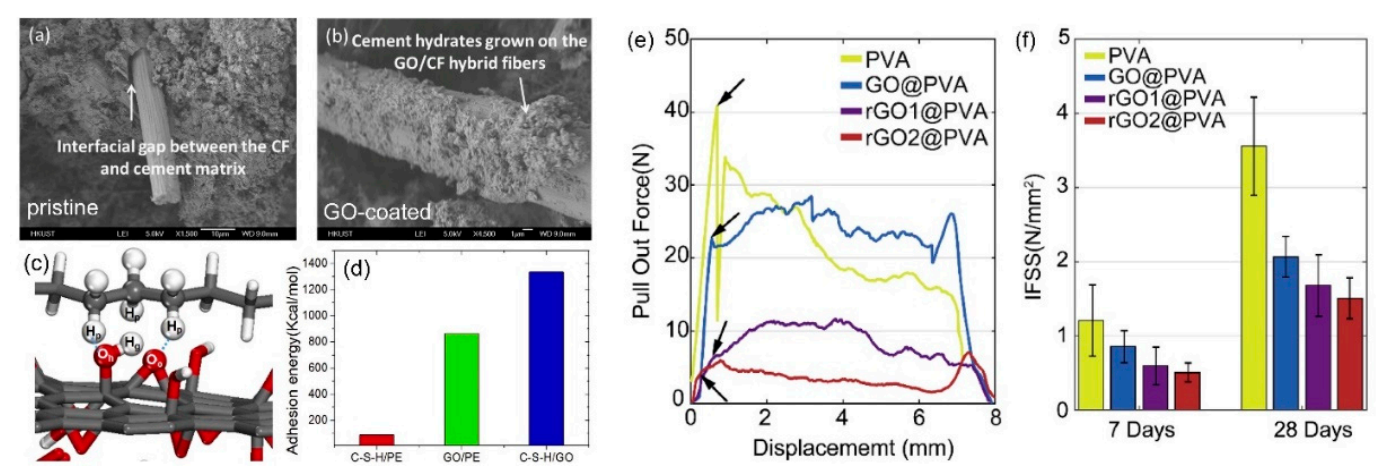

Figure 4. SEM image of fracture surface for (a) pristine and (b) GO-coated carbon fiber, respectively [38] (Copyright permission Elsevier 2018); (c) Typical pull-out force-displacement curves for the samples with 4 mm embedment after 28 days curing; (d) Interfacial shear strength of GO- and rGO-coated PVA fibers/cement composites cured for 7 and 28 days, respectively [39] (Copyright permission Elsevier 2020); (e) Pull-out simulation showing the hydrogen bonding resisting the relative sliding at the GO/PE interface; (f) Adhesion energy of interface in C-S-H/PE and C-S-H/GO/PE conditions [40] (Copyright permission Elsevier 2020). 
To quantify the interfacial properties between GO/fiber and cement matrix, Lu et al. [40] carried out MD simulations to elucidate the contribution of GO to the interfacial behavior between PE fiber and cement mortar. As presented in Figure 4c, the hydrogen bonds are formed not only between $\mathrm{GO}$ and $\mathrm{C}-\mathrm{S}-\mathrm{H}$, but also between $\mathrm{GO}$ and PE fiber. They are reversible and stable enough to resist the relative sliding of GO against the PE fiber. Quantitatively, the insertion of GO at the C-S-H/PE interface significantly improves the maximum pulling force by $42 \%$, corresponding to the increase of interfacial friction from 1.16 MPa to 1.63 MPa. Meanwhile, the adhesion energy at the interface boundary, which offers the restoring force acting on PE chains, was also extracted as shown in Figure $4 \mathrm{~d}$. While the adhesion energy for C-S-H/PE interface is only $88 \mathrm{kcal} / \mathrm{mol}$, it is enhanced to 862 and $1333 \mathrm{kcal} / \mathrm{mol}$ for GO/PE and C-S-H/GO interfaces, respectively. This suggests the critical role of GO filler in strengthening the interface connection between the PE fiber and $\mathrm{C}-\mathrm{S}-\mathrm{H}$.

Theoretically, Li et al. [68,69] developed an analytical model to predict the tensile properties of the modified FRCCs, where the total stress of the composite $\left(\sigma_{\mathrm{c}}\right)$ is assigned to three contributions: the stress in the cement matrix $\left(\sigma_{\mathrm{a}}\right)$, the bridging stress $\left(\sigma_{\mathrm{f}}\right)$, and fiber prestress $\left(\sigma_{\mathrm{ps}}\right)$. Specifically, the bridging stress is contributed by fiber reinforcement and governed by the interfacial property between the fiber and cement matrix. Based on the measurement of tensile strength of cementitious composite as well as the volume fraction and Young's modulus of fiber and matrix, the chemical bond energy between the fiber and cement matrix can be determined. Based on this model, Yao et al. [36] found that chemical bond energy for GO-coated PVA fiber/cement reached $217.8 \mathrm{~J} / \mathrm{m}^{2}$, almost 80 times that of pristine PVA fiber/cement with a chemical bond energy of $2.7 \mathrm{~J} / \mathrm{m}^{2}$.

Yao et al. [39] performed single fiber pull-out test for GO-modified PVA fiber embedded in Ordinary Portland cement (OPC). By recording the maximum pull-out force (Figure 4e), the interfacial shear strength (IFSS) can be obtained based on known fiber diameter and embedded length [70,71]. Interestingly, as shown in Figure 4f, the IFSS for GO- and rGO-coated fiber/cement samples cured for 7 days exhibit even lower values than pristine fiber/cement systems. Similar IFSS trends can also be found in samples cured for 28 days (Figure 4f). One possible reason is that the stacks of multiple GO flakes are subjected to an interlayer slip under the shear loading in pull-out test. It has been reported that the interlayer shear strength between GO and rGO layers are relatively weak, while the topological defects would further cause a drastic reduction in interlayer shear strength [72,73]. Hence, while GO layers can form strong hydrogen bonds with both PVA and C-S-H, they might suffer from the cohesive failure prior to the adhesive failure, leading to the low IFSS.

The incorporation of GO coating not only affects the interfacial load transfer, but also regulates the microstructures and mechanical properties of cement in the interfacial transition zone (ITZ). In this regard, a low-melting-point intrusion method was exploited to characterize the ITZ structures surrounding the GO/PVA fiber. Backscattered electrons (BSE) image of the cross-sections of the ITZ is given in Figure 5a, showing the spatial distribution of the pore diameter $(\mathrm{dp})$. In the case of pristine fibers, a number of large pores with $\mathrm{dp}>40 \mathrm{~mm}$ are visible in the ITZ. The porosity tends to decrease with increasing distance from the fiber surface and gradually approaches the level of the bulk cement. Quantitatively, the percentage of small pores is $(0.1 \mathrm{~mm}<\mathrm{dp}<1 \mathrm{~mm})$ is summarized as $\sim 25 \%$ as shown in Figure $5 \mathrm{~b}$. By contrast, the sample with GO coating manifests an enhanced percentage of $\sim 35 \%$ for small pores but a significant reduction in large pores. Consequently, the overall porosity is found to be greatly declined as seen in the inset, indicating of a densification effect of GO. However, due to the removal of oxygencontaining functional groups by reduction, an opposite trend is observed for rGO samples. 
(a)

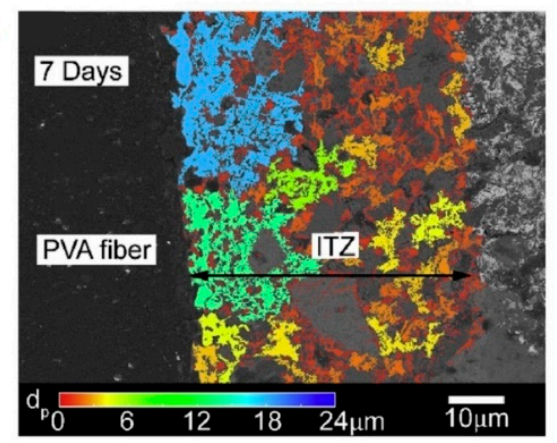

(c)

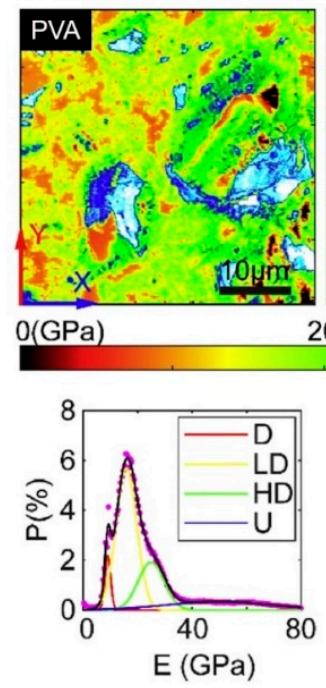

(b)

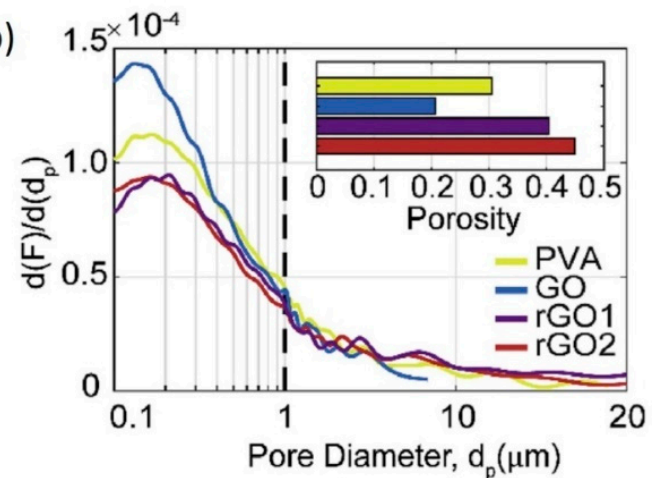

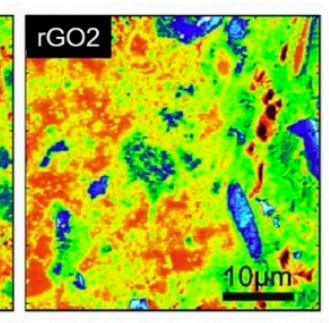
$>80$
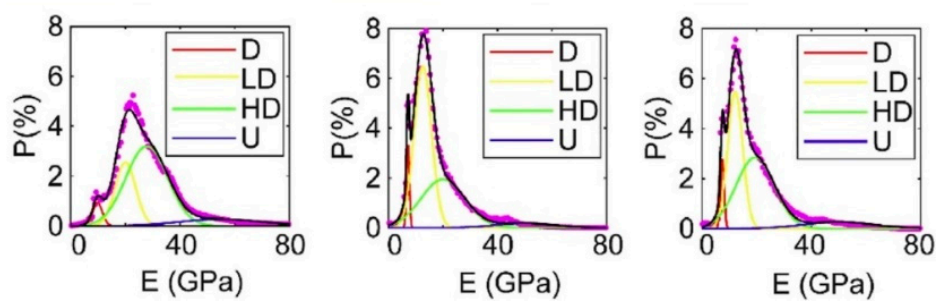

Figure 5. (a) BSE images of ITZ of PVA fiber/cement samples cured for 7 days, showing a color map of the equivalent pore diameters (dp); (b) Pore size distribution for various composite samples cured for 7 days. Inset shows the overall porosity of corresponding ITZs; (c) PeakForce QNM contour maps of the elastic modulus of the ITZ between cement and fibers and corresponding probability distribution of different phases in QNM contour maps, including holes and defects (D), low-density hydration product (LD), high-density product (HD) and unhydrated grains (U) [39] (Copyright permission Elsevier 2020).

Furthermore, the elastic properties of the ITZ were evaluated by AFM-based PeakForce Quantitative Nanomechanical Mapping (QNM) [74]. To ensure the flatness requirement for the sample, low-modulus hardened epoxy was filled into the cracks and holes. Contour maps of the elastic moduli (E) of the ITZs for different systems are presented in Figure $5 c$, wherein different phase domains can be identified, including defects ( $<12 \mathrm{GPa})$, lowdensity $(13<\mathrm{E}<26 \mathrm{GPa})$ and high-density $(26<\mathrm{E}<39 \mathrm{GPa}) \mathrm{C}-\mathrm{S}-\mathrm{H}$ as well as unhydrated grains ( $\mathrm{E}>39 \mathrm{GPa}$ ) [52]. Remarkably, the addition of $\mathrm{GO}$ coating results in a decrease of the percentage of defects from $16.4 \%$ to $5.3 \%$, while the percentage of $\mathrm{C}-\mathrm{S}-\mathrm{H}$, including both low-density and high-density, increases from $70.22 \%$ to $73.8 \%$ in the ITZ. This coincides well with the filling effect as discussed in Section 3.2. On the contrary, the reduction of GO appears to increase the percentage of holes and reduce the percentage of $\mathrm{C}-\mathrm{S}-\mathrm{H}$ in ITZ.

We can conclude that enhancement of interfacial properties between GO-coated fibers and cement can be ascribed to more efficient load transfer at the fiber/cement interface due to increased interfacial shear strength and adhesion resulting from the formation of chemical bonding as well as increased friction on the fiber surface. This implies that the control of functionalization and thickness of graphene flakes may serves as a tuning strategy to achieve optimized interfacial properties $[75,76]$. 


\subsection{Mechanical Properties}

Extensive studies have reported the incorporation of graphene as reinforcing fillers accounts for substantial enhancement of mechanical properties of cement materials [77-79]. The mechanical reinforcing mechanisms are mainly ascribed to the nucleation effect, filling effect, interfacial bonding effect, and toughening effect, as summarized in Section 3. The performance of cement-based materials is commonly evaluated from mechanical properties that include elastic modulus, tensile strength, compressive strength, and flexural strength, among which compressive and flexural strength are deemed as an indexing property and serve as the evaluation criteria for whether the cement can satisfy the engineering requirements.

One representative example is GO-coated CF reinforced cement paste which shows improvements in both flexural and compressive strength (Figure 6a,b) [37]. Specifically, GO-CF ( 0.4 wt.\%)/cement cured for 28 days exhibits the highest flexural strength of $\sim 7 \mathrm{MPa}$ and compressive strength of $\sim 30 \mathrm{MPa}$, yet the mechanical enhancement appears inconspicuous. Similar strengthening phenomena in GO-CF (1.0 wt.\%)/cement composites were also reported by $\mathrm{Lu}$ et al. [38], who performed GO coating with a newly designed EPD method. Figure $6 c$ shows experimental results of compressive strength and flexural strength of cement paste reinforced by the $\mathrm{CF}$ and GO/CF fibers. Here, GO/CF-cement corresponds to the GO/CF in aqueous solution while GO/CF-GO-cement samples are obtained by dispersing $\mathrm{GO} / \mathrm{CF}$ fibers first in $\mathrm{GO}$ solution and then mixed with cement powders, to achieve a better dispersion due to stronger electrostatic repulsion and steric stabilization. Compared with the control groups, GO/CF fibers bring a much higher compressive and flexural strength to the cement paste. The reasons can be attributed to the abovementioned reinforcing mechanisms as well as the extraordinary mechanical properties of GO itself. In addition, a better dispersion of GO/CF fibers in GO solutions further enhances the mechanical performance of cement paste. Obviously, the highest compressive and flexural strength are achieved by GO/CF-GO-cement, as high as $40.3 \mathrm{MPa}$ and 18.2 MPa respectively. This results in $14.8 \%$ and $8.7 \%$ increase respectively in contrast to the control cement paste, showing a compressive strength of $29.8 \mathrm{MPa}$ and flexural strength of $11.1 \mathrm{MPa}$. By directly mixing GO solution (0.06 wt.\%) with CF (1.0 wt.\%)/cement, Chen et al. [41] reported a $23.9 \%$ increase in compressive strength and more than $100 \%$ increment in flexural strength. It was found that the compressive strength is only affected by the presence of GO, whereas $\mathrm{CF}$ play a joint role in flexural strength. With increasing GO content from $0.06 \%$ to $1.0 \%$, the mechanical enhancement of compressive and flexural strength can be further elevated to $46.9 \%$ and $43.6 \%$, respectively. 

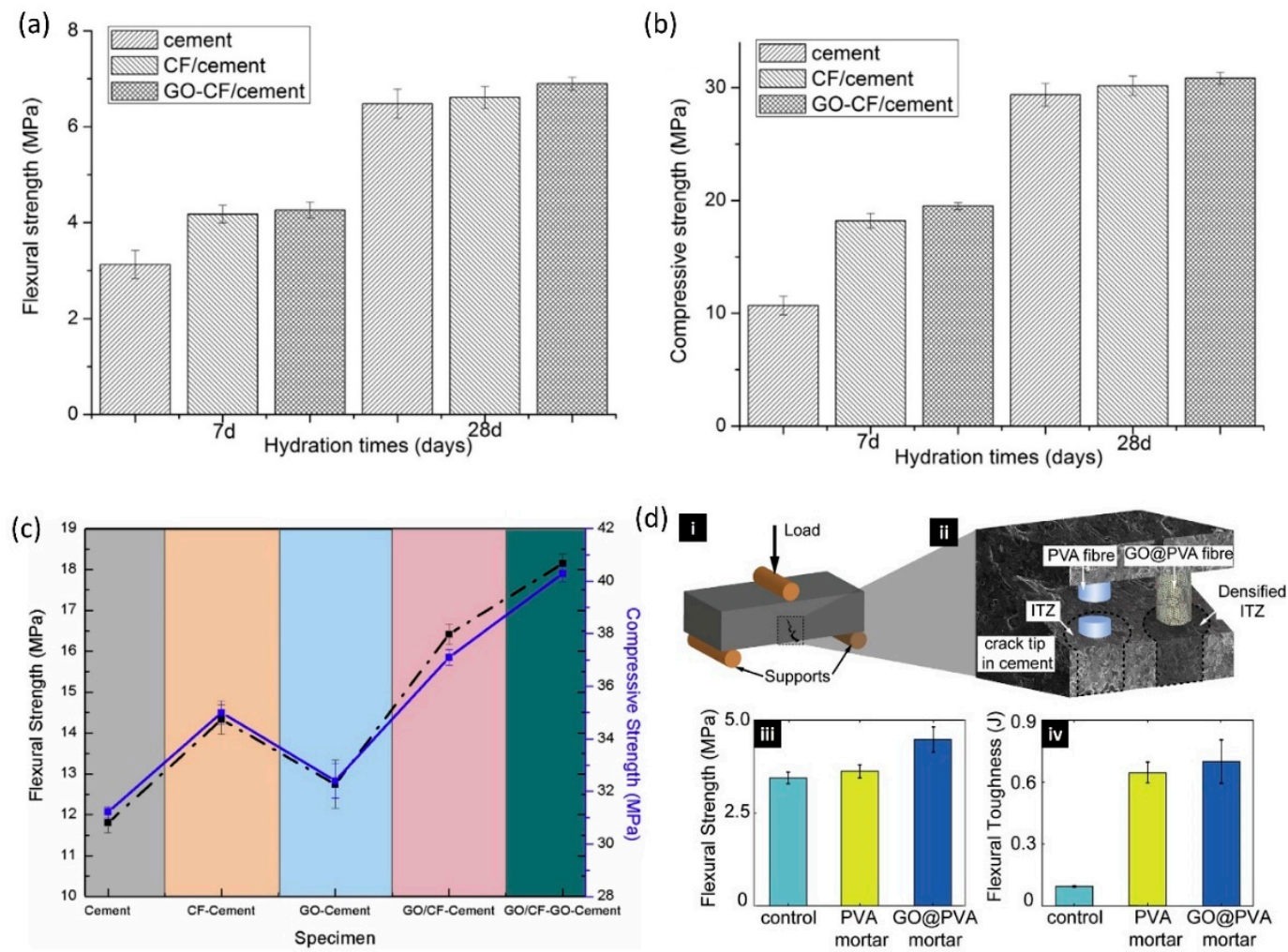

Figure 6. (a) Flexural and (b) compressive strength of the cement paste (with $0.4 \mathrm{wt} . \% \mathrm{CF} / \mathrm{GO}-\mathrm{CF}$ ) at 7 days and 28 days [37] (Copyright permission Elsevier 2015); (c) Flexural and compressive strength of GO/CF/cement specimens [38]; (d) Measurement of flexural strength and toughness of GO/PVA/cement by a three-point bending test [39] (Copyright permission Elsevier 2020).

Comparatively, different enhancements in mechanical properties of GO-CF/cement composites are reported. Potential reasons can be attributed to the differences in sizes, filler content, and functionalized degree of GO, as well as the degree of dispersion. As expected, larger surface area can benefit the nucleation effect and interfacial bonding effect, and good dispersion is favorable of the toughening effect and filling effect. Likewise, a higher concentration of graphene in the cement matrix can also bring forth a pore filling effect, more compact and refined structures in cement composites, leading to a better mechanical performance.

Yao et al. [39] carried out three-point bending tests to explore the effect of GO on the mechanical performance of PVA fiber-reinforced cementitious composites, as shown in Figure $6 \mathrm{~b}$. The incorporation of pristine PVA fibers in cement mortar can mildly increase its flexural strength by only $\sim 5 \%$. In contrast, GO coating on PVA fibers makes the flexural strength dramatically increase up to $4.49 \mathrm{MPa}$ for GO@PVA mortar. A more significant reinforcing effect is found in flexural toughness, which is calculated based on the area under load-deflection curves. As shown in Figure 6d(iv), the flexural toughness is growing from $\sim 0.1 \mathrm{~J}$ for plain cement mortar to $0.64 \mathrm{~J}$ for PVA mortar, and finally reaches $0.704 \mathrm{~J}$ for GO@PVA mortar. Such a ductile behavior came from the relatively weak interfaces between fiber and cement which is associated to the energy dissipation mechanism.

Tensile strength of FRCC is one of the major parameters to measure mechanical properties. Uniaxial tensile test is a common way to measure the tensile properties of cementitious composites. Figure 7a displays typical stress-strain curves of cement mortar reinforced by PE and GO/PE fibers in uniaxial tensile tests. Multiple drops can be visible which suggest a series of cracking during the deformation, due to the porous nature of cement mortar. It is clear that the first cracking strength of GO/PE-Mortar is around 4.9 $\mathrm{MPa}$, almost $12 \%$ higher than that of PE-Mortar (4.4 MPa). In addition, the tensile strength 
(maximum tensile stress) can reach $10.4 \mathrm{MPa}$, which is $46.3 \%$ improvement compared to the PE-Mortar (7.1 MPa). The most salient feature is the ultimate tensile strain, showing a $70.4 \%$ enhancement from 3.75\% (PE-Mortar) to 6.39\% (GO/PE-Mortar). Such strain-hardening properties of mortar are attributed to the densified microstructures and improved bonding at ITZ [40]. Yao et al. [36] also studied the splitting tensile strength of the GO/PVA fiberreinforced cementitious composites. As shown in Figure $7 \mathrm{~b}$, the introduction of pristine PVA fibers can increase the tensile strength of the 7-day and 35-day samples by $16.8 \%$ and $4.1 \%$, respectively, compared with the plain cements. With the GO modification, the splitting tensile strength of the 7-day samples further improves by $32.2 \%$ compared to the control group and such an enhancement rises to $41.2 \%$ after 35 -days curing. Furthermore, based on the tensile stress-strain curves and starting from the theoretical model proposed by $\mathrm{Li}$ et al. [68,69] as discussed in Section 4.1, Yao et al. [39] estimated the tensile strength of PVA fiber/cement composites to be $6.18 \mathrm{MPa}$, which was increased to $7.83 \mathrm{MPa}$ after introducing the GO coating. Meanwhile, an enhancement of toughness was deduced, from 2.94 to $33.16 \mathrm{~kJ} / \mathrm{m}$. Conclusively, the GO modification of PVA fibers can simultaneously improve the mechanical strength and toughness for FRCC.

(a)

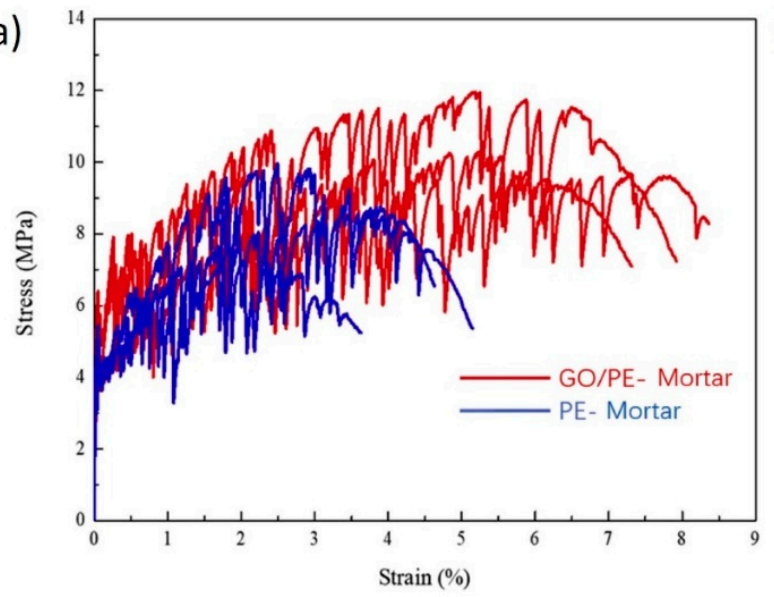

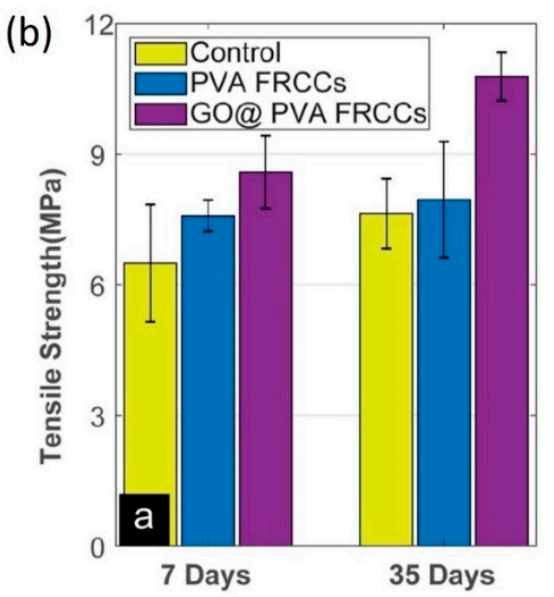

Figure 7. (a) Stress-strain curves of mortar with PE and GO/PE fibers in uniaxial tensile tests [40] (Copyright permission Elsevier 2020); (b) Measurement of tensile strength for GO/PVA FRCC [36] (Copyright permission Elsevier 2019).

It can be concluded that the intensified mechanical reinforcing effect can be associated with four aspects: (1) The ultrahigh stiffness and strength of graphene itself; (2) Strengthening of the fiber interface properties that allows a higher load carrying capability of fibers in the composite; (3) Stiffening of cement matrix within the ITZ by densification of microstructures; (4) Toughening mechanism provided by graphene and fibers. In this respect, it can be envisioned that moderate reduction of GO would benefit the mechanical enhancement, as it restores the hexagonal structures of pristine graphene by eliminating defects while maintaining adequate surface functional groups to keep strong bonding with cement matrix. Besides, the modifying effect of ITZ to cementitious composites is anticipated to be enhanced with increasing graphene content if the dispersion issue can be well addressed.

Such design principles can also be extended to other building materials, such as geopolymers. Geopolymer composites are the most promising environmentally friendly alternative to traditional cement materials (e.g., Portland cement) [80]. Given the high quasi-brittle behavior of geopolymers (due to their ceramic-like characteristics), fibers and graphene-based materials have been used as reinforcements to produce stronger and tougher composites, showing tremendous potential in a broad spectrum of applications including supercapacitors, fire-resistant coating, and so forth [81-84]. It can be envisaged that the hybrid graphene-fiber reinforcements will further improve the mechanical and 
durability performance of geopolymer composites, and endow them with functionality and versality.

\subsection{Durability Performance}

The durability performance of cement-based materials has long been a major concern in the construction industry especially considering their susceptibility and vulnerability to aggressive environments. From the structural point-of-view, the durability of cementitious composites is primarily affected by the porosity characteristics, which play as a dominant role for both mechanical and chemical durability performance [85]. It has been documented that pores having sizes larger than $20 \mathrm{~nm}$ would act as channels within the cement, through which water molecules and aggressive chemical species diffuse [86]. In this respective, the addition of graphene fillers can increase the resistance to permeability and relevant corrosion, thus improving the durability performance of FRCC.

In order to investigate the impermeability of cementitious composites, Jiang et al. conducted rapid chloride migration tests and measured chloride migration coefficient $\left(D_{C l}\right)$, which is one of the important indexes to characterize the resistance to chloride ion permeation of cement-based materials. As shown in Figure 8a, adding either PVA fibers or $\mathrm{GO}$ alone can effectively reduce the $\mathrm{D}_{\mathrm{Cl}}$, yet $\mathrm{GO}$ shows a higher efficiency with a decreasing magnitude of $35.6 \%$. Obviously, the combination of GO and PVA leads to the most significant decrease from $7.3 \times 10^{-12}$ to $4.3 \times 10^{-12} \mathrm{~m}^{2} \cdot \mathrm{s}^{-1}$, implying the highest impermeability of GO/PVA/cement system.

(a)

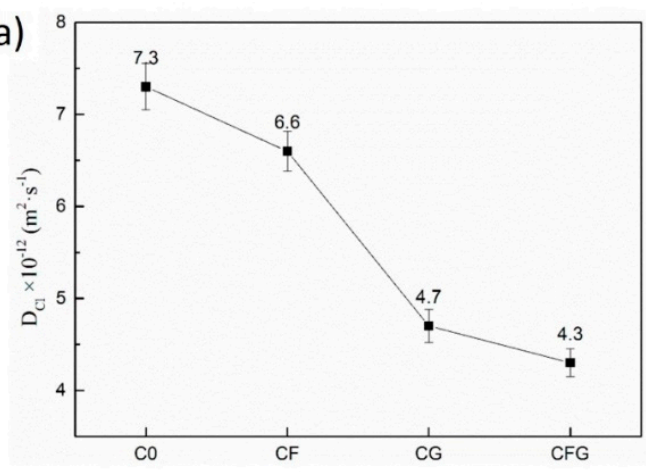

(c)

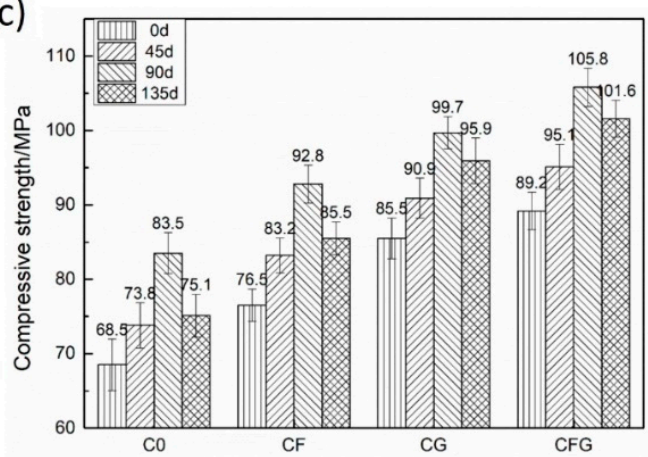

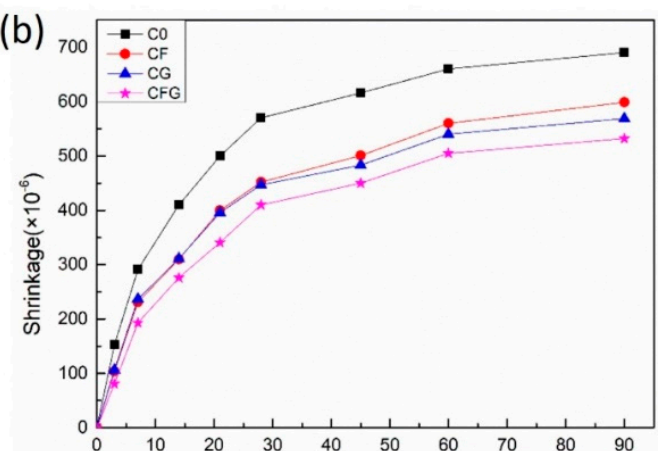

(d)

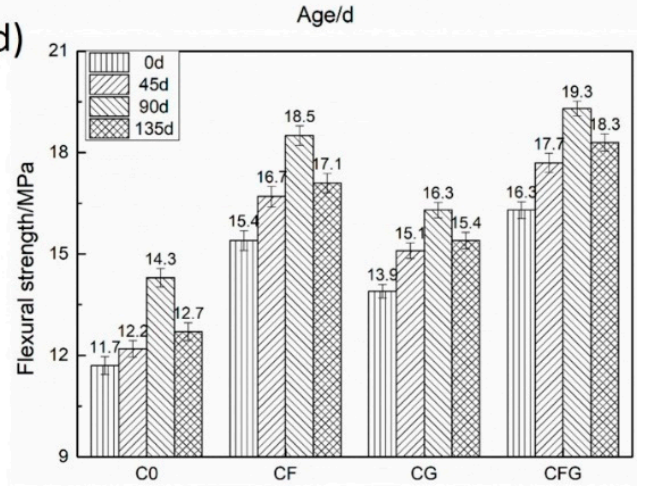

Figure 8. (a) Chloride migration coefficient of cementitious composite; (b) Drying shrinkage rate of specimens at different ages; (c) Compressive strength and (d) flexural strength of samples under the sulfate corrosion condition [42]. C0: control sample; CF: PVA fiber/cement; CG: GO/cement; CFG: GO/PVA fiber/cement.

When the cement materials are exposed to a low-humidity environment, water evaporation usually occurs from the capillary pores to result in the drying shrinkage [87]. The pore size determines the capillary force which holds the water in the capillary holes. Smaller pores are expected to induce larger capillary force. Therefore, the filling effect of $\mathrm{GO}$ will be instrumental to the suppression of shrinkage and the mechanical enhancement 
further increases the resistance of cement-based materials matrix to shrinkage. As a result, the 90-day shrinkage of GO/cement composite is found to decrease by $17.5 \%$ compared with control sample (Figure $8 \mathrm{~b}$ ). It has also been demonstrated that fibers play a role in restraining shrinkage by shear deformation along the interface [88]. The coupling effect of GO and PVA fiber minimize shrinkage in FRCC across all ages, as presented in Figure $8 \mathrm{~b}$.

Sulfate corrosion resistance of the modified cementitious composites over a period of 135 days is reflected by the measurements of compressive and flexural strength as shown in Figure $8 \mathrm{c}$,d. Under sulfate corrosion conditions, the continuous hydration process is activated to produce more hydrates and compact mortar matrix, thus strengthening the cement materials. However, the sulfate corrosion process takes place at the same time, where the $\mathrm{SO}_{4}{ }^{2-}$ ions penetrate mortar and react with cement to produce intumescent minerals (e.g., ettringite), leading to the expansion stress and cracks in the mortar matrix. Based upon such a competing mechanism, the positive contribution dominates in the early stage of sulfate corrosion so that the mechanical strength is improved, whereas the negative factor becomes more prominent with the increase of corrosion time and finally the mechanical strength tends to decline [42]. Due to the increased impermeability with the presence of $\mathrm{GO}$, the diffusion of the $\mathrm{SO}_{4}{ }^{2-}$ ions and the generation of intumescent minerals will be limited in the mortar matrix. On the other hand, both PVA fibers and GO serve to counteract the expansion stress and restrict the crack propagation in the cement. Hence, the GO/PVA/cement mixture exhibits the highest compressive and flexural strength among all the samples at 135 days.

\subsection{Electrical Properties}

Structural health monitoring of reinforced concrete structures has garnered enormous attention from both industry and academy, which aims to monitor the actual stress states and detect damages in the built infrastructure. Apart from using external sensors, the concept of cement-based piezoresistive sensors is registering an exponentially upward trend in recent years. The prerequisite is to produce conductive cementitious composites so the stress or damages can be detected by monitoring the change of electrical resistivity. In reality, the cement-based materials are anticipated to be slightly conductive due to the ion transfer, depending on the water content stored within the cement. The overall electrical conductivity of cementitious composites tends to be elevated by increasing the porosity and hence the interconnectivity [89]. However, in order to make cementitious composite as a conductive material, a more efficient approach is incorporating conductive fillers into the cement mixture, thus conferring their conductivity.

Due to the superior electrical conductivity of graphene, graphene-based cementitious composites have been reported to have outstanding electrical properties and self-sensing ability [90,91]. However, limited by the dispersion issue, GO instead of pristine graphene is more frequently used as fillers in cementitious composites, yet it is known to increase the electrical resistance due to oxygen-containing functional groups. Gopalakrishnana et al. [92] studied the electrical properties of cement composite by imposing GO on high-volume PVA fiber-reinforced Sugarcane bagasse ash (SCBA) mortars. As depicted in Figure 9a, compared to the control sample with electrical resistivity values of 6.1 and $7.2 \mathrm{~K} \Omega \mathrm{cm}$ at 7 day and 28 day curing ages, addition of GO and PVA increases the electrical resistivity for all the mixes. When the GO/PVA ratio reaches 1.5/1.0, the largest enhancement of electrical resistivity is observed, which is $79.5 \%$ and $77.6 \%$ at 7 day and 28 day curing ages. Due to the nucleation effect, the hydration process is accelerated with the presence of GO so that the densified microstructures result in the stumbling block of pathways in cement mortar, which are important for ionic conduction. In addition, GO has a high adsorption efficiency and decreases the availability of free water in cement, which is responsible for the improved electrical resistivity as well. 

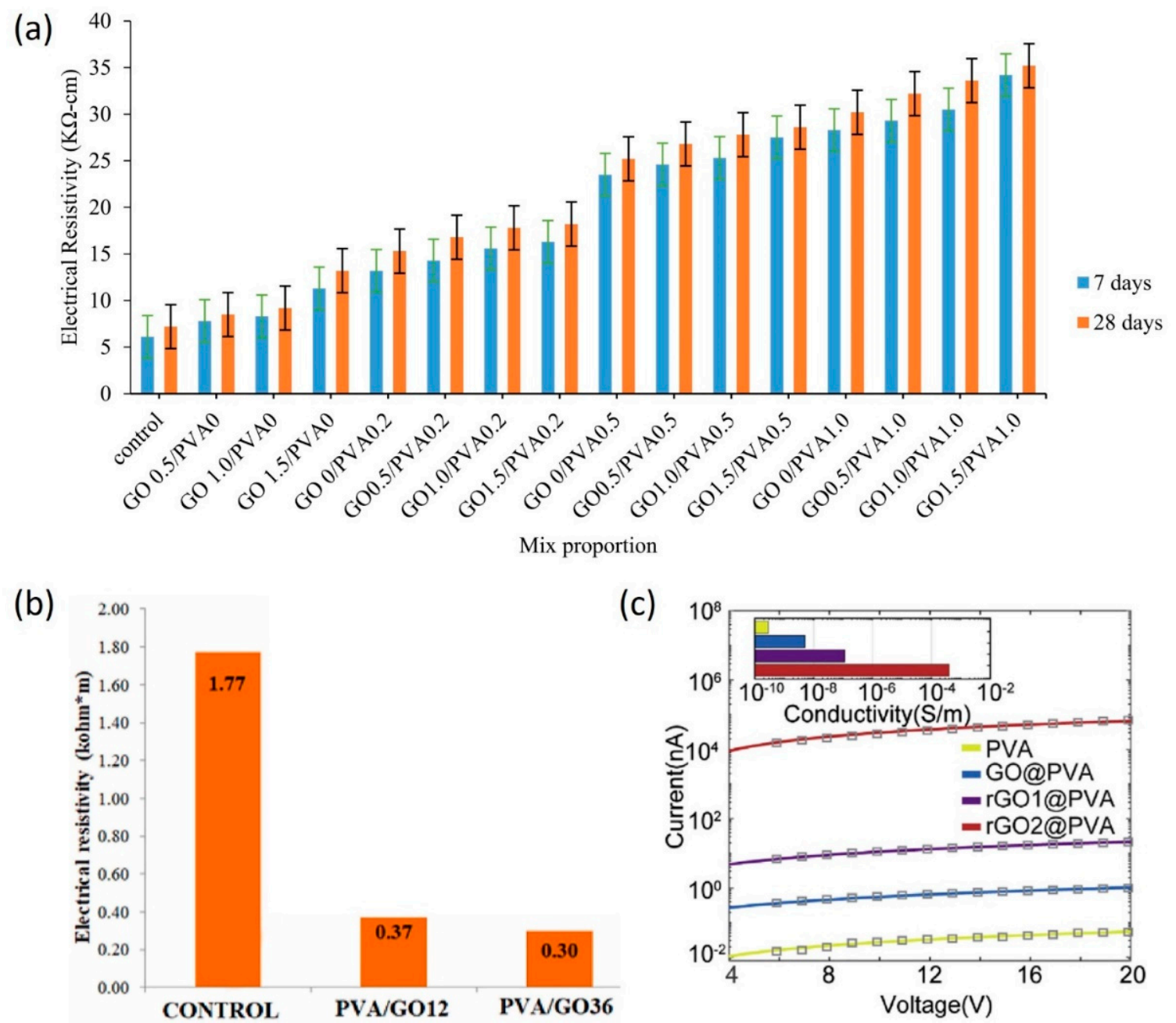

Figure 9. (a) Electrical resistivity of SCBA mortars with varied GO/PVA hybrid at the age of 7, 28 days [92] (Copyright permission Springer 2021); (b) Electrical resistivity of FRM with PVA/GO fillers [93] (Copyright permission Elsevier 2021); (c) Electrical conductivity measurement of oxidized graphene nanosheets-modified PVA fibers [39] (Copyright permission Elsevier 2020).

Nevertheless, Uygunoğlu et al. [93] reported an opposite observation on the same material composition, despite using a different preparation method of GO/PVA fillers. Therein, instead of direct mixing, they first prepared the GO/PVA composite ribbons and then mixed with cement and fly ash to obtain the composites. Consequently, a reduction of electrical resistivity was found for GO/PVA/mortar compared with control sample, as seen in Figure 9b. Increasing amount of GO from $0.012 \mathrm{~g}$ (GO12) to $0.036 \mathrm{~g}$ (GO36) further decreases the electrical resistance from $79.09 \%$ to $83.05 \%$. One possible reason lies in the formation of the hydrogen bonds between oxygen-containing functional groups on $\mathrm{GO}$ and PVA. Even though PVA is insulating, it helps create large pores and enhance the electrical resistance of cementitious composite.

In this context, replacing $\mathrm{GO}$ with $\mathrm{rGO}$ fillers can be an effective way to increase the electrical conductivity of cement composites [6]. Upon removal of oxygen functional groups, the $s p^{2}$-bonded clusters are partially restored, leading to an increase of carrier mobility of PVA fibers and correspondingly a change in their charge density. Figure $9 \mathrm{c}$ shows that the electric conductivity was boosted more than one order from $5 \times 10^{-9} \mathrm{~S} / \mathrm{m}$ for GO/PVA/cement to $10^{-7} \mathrm{~S} / \mathrm{m}$ for rGO1/PVA/cement. Moreover, in contrast to rGO1-based composite which experiences $1 \mathrm{~min}$ reduction, longer treatment time $(1 \mathrm{~h})$ for $\mathrm{rGO} / \mathrm{PVA} /$ cement composite gives a more significant enhancement of conductivity $\left(4 \times 10^{-4} \mathrm{~S} / \mathrm{m}\right)$, more than four orders higher than that of GO/PVA/cement sample [39]. 


\subsection{Electromagnetic Interference Shielding Performance}

With the advancement of modern technology, there has been a rapid growth of the electronic devices, which raise growing concerns over the electromagnetic pollution. Owing to the adverse impact of electromagnetic interference (EMI) and increased electromagnetic wave (EMW) within the atmosphere, it is imperative to provide EMI shielding for the infrastructure construction, especially for some particular buildings such as hospitals [94]. To this end, the development of cementitious materials with high shielding effectiveness (SE) has aroused tremendous attention, with a special emphasis on the addition of filler materials into the cement to enhance the SE.

Previous works have shown excellent EMI shielding effect of cementitious composites infused with graphene [95-97], having a huge potential spanning from the amelioration of electromagnetic emission problems on human health to the prevention of information leakage in the military field. Typical EMI shielding mechanism for the graphene-based cementitious composites can be summarized as: (1) Barrier effect of well-dispersed graphene to block EMW transmission; (2) Energy dissipation and frequency weakening of EMW during multiple reflection and refraction on randomly oriented graphene surface; (3) Absorption of EMW due to the dielectric characteristics of graphene [78]. While conductive fibers (e.g., carbon fibers and steel fibers) have been confirmed to help increase the EMI shielding performance of cementitious composite [98], the incorporation of graphene is believed to enhance the EMI SE to a higher level. For example, Chen et al. [37] introduced GO-deposited CF into cementitious composites and studied its enhancement of the EMI shielding performance. As seen in Figure 10a, apparently, the SE of CF/cement composite is rising with increasing amount of $\mathrm{CF}$. A similar trend can be observed for $\mathrm{GO}-\mathrm{CF} /$ cement as well in Figure 10b, while GO-CF presents an even more significant improvement in SE, especially when the mass fraction is beyond $0.2 \%$. Particularly, at the mass fraction of $0.4 \%$, $\mathrm{SE}$ of GO-CF/cement composite reaches as high as $34 \mathrm{~dB}$, corresponding to a $278 \%$ increase than that of control sample without GO.

Generally, there are three major mechanisms involved in EMI shielding, including reflection (SER), absorption (SEA), and multiple reflections (SEMR), which are related to mobile charge carriers, electric (or magnetic) dipoles, and reflections at various surfaces or interfaces [99,100]. Mostly, the synergy effect among several shielding mechanisms contributes to the attenuation of EMW. As demonstrated previously, the multiple reflections and scattering are crucially important for shielding mechanisms, where EMW reflects at multi-interfaces in an EMI shielding material. However, when the SEA is larger than 10 $\mathrm{dB}$, the SEMR can be insignificant [95]. Figure 10c-f display the SEA and SER results for $\mathrm{CF} /$ cement composite and GO-CF/cement composite, respectively. The SER values are within 2-4 dB for both composite systems; however, while the SEA for CF/cement composite is found to range from 7 to $22 \mathrm{~dB}, \mathrm{GO}-\mathrm{CF} /$ cement elevates it up to $30 \mathrm{~dB}$ at $0.4 \%$ content. It is hence concluded that absorption acts as the dominant mechanism in shielding. Furthermore, the higher SE achieved for GO can be originated from the defects and functional groups. On one hand, defects are considered as polarization centers. They can induce polarization relaxation under the alternating electromagnetic field and aid the attenuation of EMW [101]. On the other hand, carbon and oxygen atoms in the oxygen-containing functional groups have distinct electron capture capability, thus creating the electric dipole polarization. Under altering electromagnetic field, the electron motion hysteresis in these dipoles will cause extra polarization relaxation that facilitate the absorption [102]. 

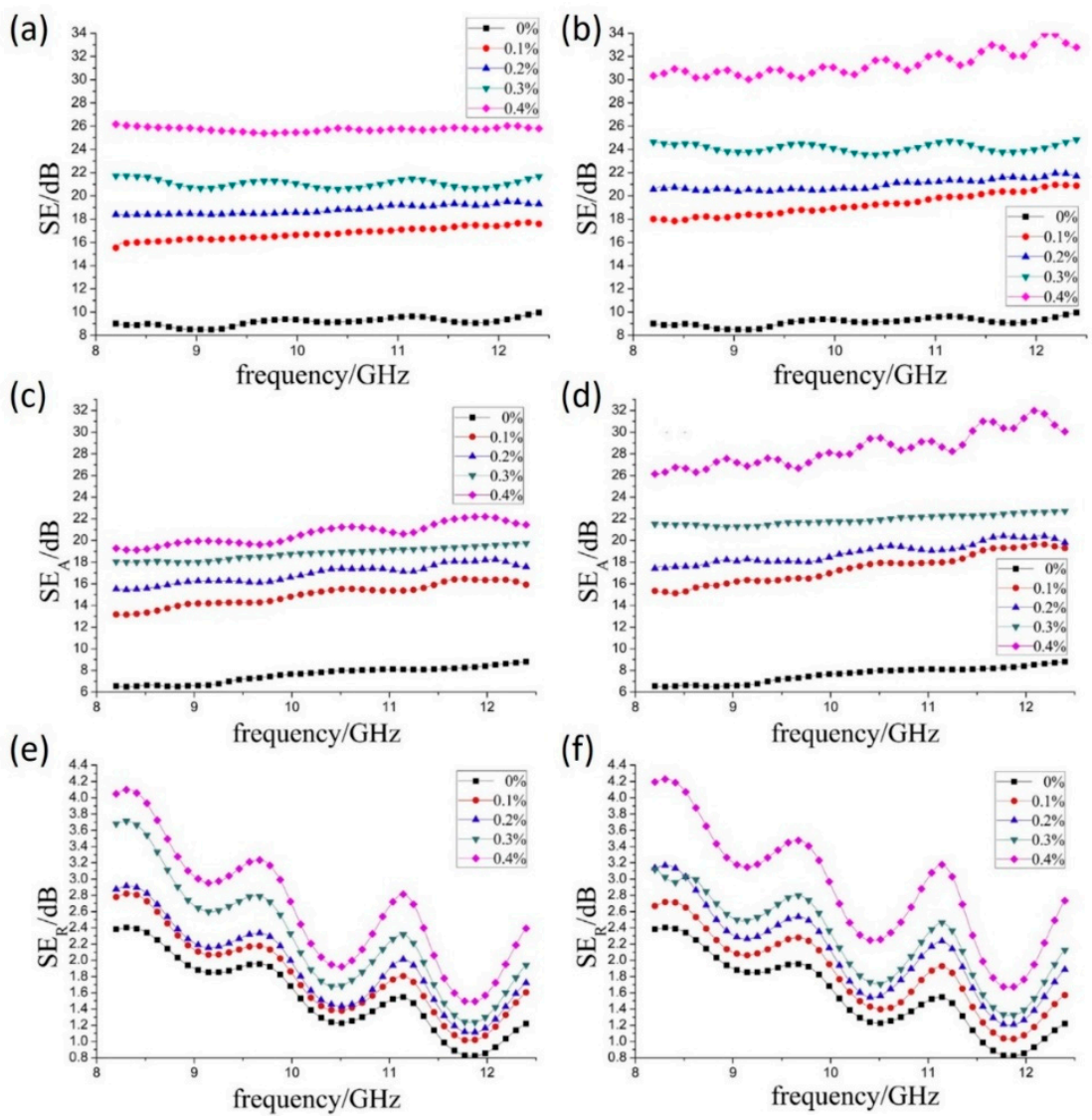

Figure 10. Variation of SE with frequency for (a) CF/cement and (b) GO-CF/cement composite with different mass fraction of fiber; Analysis of SEA for (c) CF/cement and (d) GO-CF/cement composite and SER for (e) CF/cement and (f) GO-CF/cement composite, respectively [37] (Copyright permission Elsevier 2015).

According to Simon formalism [103], The EMI SE is also strongly dependent on the electrical conductivity of EMI materials. Although the defects and oxygen-containing functional groups of GO are responsible for EMI shielding, they disrupt $s p^{2}$-bonded networks and endow GO with a relatively poor electrical conductivity compared with pristine graphene. In this scenario, rGO that partially restores the aromatic graphene structure looks more promising in EMI shielding performance, as it not only recovers electrical conductivity to build a more effective conductive network, but also retains structural features of GO which favor the dispersion of fiber as well as the polarization relaxation process [56]. Additionally, the wrinkled rGO sheets can increase the surface roughness of $\mathrm{CF}$ and trigger the mechanical interlocking effect within the cement. The conductive networks are reported to be robust enough to provide sufficient paths to transport charge carriers, which increases the shielding properties of the rGO modified FRCC composites [104].

\section{Conclusions and Outlook}

Research in recent years has demonstrated the great potential of graphene in the field of construction materials. In this study, we have provided a full account of the application of graphene-based materials in FRCC, which represents a novel approach and an emerging area in advanced construction materials technology.

In addition to the direct mixing method, preparation of graphene coating on fibers affords a more efficient way to manufacture the hybrid graphene-fiber fillers. Commonly used coating methods, such as dip coating and electrophoretic deposition, were reported to produce a uniform and conformable graphene layer on the fibers, which is critical to the overall performance of cementitious composites. It can be concluded from the literature 
that graphene can act as nucleation sites to promote the hydration of cement. Due to the combined action by such a nucleating and filling effect of graphene, the porosity of the cementitious composites can be greatly reduced, featuring with densified microstructures within the ITZ. The addition of graphene fillers (especially GO) in FRCC will also promote the interfacial interactions by establishing chemical bonding network as well as inducing the mechanical interlocking effect. More importantly, synergistic strengthening and toughening can be achieved in FRCC with the presence of graphene, thanks to its offered extra energy dissipation mechanisms (e.g., crack deflection, branching, bridging, etc.) to retard the crack propagation. Consequently, the incorporation of graphene-based fillers reveals their considerable potential for the improvement in compressive strength, flexural strength, tensile strength, and durability of FRCC. In addition, other functional properties such as electrical and electromagnetic interference (EMI) shielding performance are simultaneously enhanced with the assistance of graphene, thanks to its high electrical conductivity and barrier effect.

Our study advances the fundamental understanding of the nanoscale reinforcing mechanisms, correlating the microscopic phenomena with the macro-performance of the cementitious composite. This enables us with an opportunity to design the high-performance cementitious composites through the rationalized optimization of the lateral size, thickness, functionalized degree, and filler content of graphene, as well as interface interactions between both graphene/fiber and graphene/cement. As per the recent studies reviewed in this article, hybrid graphene-fiber reinforced cementitious composite outperforms those with single-phase fillers, highlighting the complementary and synergistic contributions of graphene and fiber to the enhancement of properties and performance of cementitious composite. Furthermore, the existing standard manufacturing process of FRCC using industrial-scale equipment in a streamlined manner would boost the industrialization progress of hybrid graphene-fiber reinforced cementitious composite.

Hybrid graphene-fiber reinforced cementitious composites will be able to accelerate the advancement of a new generation of construction materials, serving their fabulous multifunctionality for more economical, durable, safer, and smarter infrastructure systems. However, before this can happen, there still remain challenges hindering the implementation of graphene-based materials in the construction materials, which still need to be resolved. One of the main difficulties is related to synthesis of graphene materials, regarding the control of quality (e.g., size, thickness, defects, etc.), cost, scalability, reproducibility, and sustainability on the industrial scale. In terms of the quality control, progress has been made to minimize defects in GNP sheets. Nanoplatelets with improved graphitic quality can be produced by microwave heating or by high-temperature annealing. There is still a pressing need for the establishment of industrial standards for graphene products. Full transparency on the materials characterization (e.g., Raman spectroscopy, interference reflection microscopy, etc.) of graphene products is also required. To increase environmental friendliness and sustainability, green synthesis of graphene materials needs to be developed, for example, by using bio-related materials and non-hazardous chemicals as reducing agents. The reduction in graphene materials production cost is also one of the priorities for industrial-scale development. Although the cost of infusion of graphene in cement materials is indeed higher compared to plain cement composites, the extra expenditure on the repair and maintenance can be offset from a long-term perspective of infrastructure lifecycle. Furthermore, in contrast with the amount of GO directly incorporated into cement matrix, much less amount of GO is required for coating fibers, which can contribute to the mechanical enhancement of cementitious composites. On the other hand, the dispersion challenge has always been the bottleneck for the application of graphene and fiber in composite materials, especially considering the target at high concentrations. In fact, coating graphene on fibers aids to alleviate the dispersion issues. In addition, surface functionalization can further enhance the compatibility between the filler and cement matrix. With growing nanotechnology knowledge, it is expected that graphene applications for the development of novel construction materials will become 
more widespread in the construction field, yet research is still required in the formulation of practical graphene-based products before commercially viable materials can be developed.

Author Contributions: Investigation, S.W.; supervision, G.W.; writing-original draft, S.W. and G.W.; writing - review and editing, T.Q. and G.W. All authors have read and agreed to the published version of the manuscript.

Funding: This research was funded by Anhui Provincial Humanities and Social Research Project (SK2016a0510).

Acknowledgments: The authors are grateful for Tanvir Qureshi's IFA: New Starters (Faculty funded) award by the University of the West of England, Bristol, UK.

Conflicts of Interest: The authors declare no conflict of interest.

\section{References}

1. Qureshi, T.S.; Panesar, D.K. Nano reinforced cement paste composite with functionalized graphene and pristine graphene nanoplatelets. Compos. B Eng. 2020, 197, 108063. [CrossRef]

2. Anwar, A.; Mohammed, B.S.; Wahab, M.A.; Liew, M.S. Enhanced properties of cementitious composite tailored with graphene oxide nanomaterial-A review. Dev. Built Environ. 2020, 1, 100002. [CrossRef]

3. Li, X.; Liu, Y.M.; Li, W.G.; Li, C.Y.; Sanjayan, J.G.; Duan, W.H.; Li, Z. Effects of graphene oxide agglomerates on workability, hydration, microstructure and compressive strength of cement paste. Constr. Build. Mater. 2017, 145, 402-410. [CrossRef]

4. Gao, D.; Zhang, L.; Nokken, M. Mechanical behavior of recycled coarse aggregate concrete reinforced with steel fibers under direct shear. Cem. Concr. Compos. 2017, 79, 1-8. [CrossRef]

5. Foglar, M.; Hajek, R.; Fladr, J.; Pachman, J.; Stoller, J. Full-scale experimental testing of the blast resistance of HPFRC and UHPFRC bridge decks. Constr. Build. Mater. 2017, 145, 588-601. [CrossRef]

6. Chen, J.; Wu, J.; Ge, H.; Zhao, D.; Liu, C.; Hong, X. Reduced graphene oxide deposited carbon fiber reinforced polymer composites for electromagnetic interference shielding. Compos. A Appl. Sci. Manuf. 2016, 82, 141-150. [CrossRef]

7. Stynoski, P.; Mondal, P.; Marsh, C. Effects of silica additives on fracture properties of carbon nanotube and carbon fiber reinforced Portland cement mortar. Cem. Concr. Compos. 2015, 55, 232-240. [CrossRef]

8. Lu, C.; Lu, Z.; Li, Z.; Leung, C.K. Effect of graphene oxide on the mechanical behavior of strain hardening cementitious composites. Constr. Build. Mater. 2016, 120, 457-464. [CrossRef]

9. Pakravan, H.; Latifi, M.; Jamshidi, M. Hybrid short fiber reinforcement system in concrete: A review. Constr. Build. Mater. 2017, 142, 280-294. [CrossRef]

10. Piggott, M.R. Load Bearing Fibre Composites; Springer Science \& Business Media: Berlin, Germany, 2002.

11. Singh, S.; Shukla, A.; Brown, R. Pullout behavior of polypropylene fibers from cementitious matrix. Cem. Concr. Res. 2004, 34, 1919-1925. [CrossRef]

12. Stang, H.; Shah, S. Failure of fibre-reinforced composites by pull-out fracture. J. Mater. Sci. 1986, 21, 953-957. [CrossRef]

13. Bhogayata, A.C.; Arora, N.K. Fresh and strength properties of concrete reinforced with metalized plastic waste fibers. Constr. Build. Mater. 2017, 146, 455-463. [CrossRef]

14. Ahmed, H.U.; Faraj, R.H.; Hilal, N.; Mohammed, A.A.; Sherwani, A.F.H. Use of recycled fibers in concrete composites: A systematic comprehensive review. Compos. B Eng. 2021, 215, 108769. [CrossRef]

15. Wang, G.; Liu, L.; Dai, Z.; Liu, Q.; Miao, H.; Zhang, Z. Biaxial compressive behavior of embedded monolayer graphene inside flexible poly (methyl methacrylate) matrix. Carbon 2015, 86, 69-77. [CrossRef]

16. Wang, G.; Dai, Z.; Wang, Y.; Tan, P.; Liu, L.; Xu, Z.; Wei, Y.; Huang, R.; Zhang, Z. Measuring interlayer shear stress in bilayer graphene. Phys. Rev. Lett. 2017, 119, 036101. [CrossRef]

17. Wang, G.; Li, X.; Wang, Y.; Zheng, Z.; Dai, Z.; Qi, X.; Liu, L.; Cheng, Z.; Xu, Z.; Tan, P.-H. Interlayer coupling behaviors of boron doped multilayer graphene. J. Phys. Chem. C 2017, 121, 26034-26043. [CrossRef]

18. Duan, F.; Li, W.; Wang, G.; Weng, C.; Jin, H.; Zhang, H.; Zhang, Z. Can insulating graphene oxide contribute the enhanced conductivity and durability of silver nanowire coating? Nano Res. 2019, 12, 1571-1577. [CrossRef]

19. Dai, Z.; Wang, G.; Zheng, Z.; Wang, Y.; Zhang, S.; Qi, X.; Tan, P.; Liu, L.; Xu, Z.; Li, Q.; et al. Mechanical responses of boron-doped monolayer graphene. Carbon 2019, 147, 594-601. [CrossRef]

20. Lee, C.; Wei, X.; Kysar, J.W.; Hone, J. Measurement of the elastic properties and intrinsic strength of monolayer graphene. Science 2008, 321, 385-388. [CrossRef]

21. Lee, G.H.; Cooper, R.C.; An, S.J.; Lee, S.; van der Zande, A.; Petrone, N.; Hammerherg, A.G.; Lee, C.; Crawford, B.; Oliver, W.; et al. High-Strength Chemical-Vapor Deposited Graphene and Grain Boundaries. Science 2013, 340, 1073-1076. [CrossRef]

22. Cui, T.; Mukherjee, S.; Sudeep, P.M.; Colas, G.; Najafi, F.; Tam, J.; Ajayan, P.M.; Singh, C.V.; Sun, Y.; Filleter, T. Fatigue of graphene. Nat. Mater. 2020, 19, 405-411. [CrossRef]

23. Gao, Y.; Liu, L.-Q.; Zu, S.-Z.; Peng, K.; Zhou, D.; Han, B.-H.; Zhang, Z. The effect of interlayer adhesion on the mechanical behaviors of macroscopic graphene oxide papers. ACS Nano 2011, 5, 2134-2141. [CrossRef] 
24. Zhang, Y.; Liu, L.; Sun, B.; Wang, G.; Zhang, Z. Preparation of lipophilic graphene oxide derivates via a concise route and its mechanical reinforcement in thermoplastic polyurethane. Compos. Sci. Technol. 2016, 134, 36-42. [CrossRef]

25. Lv, S.; Ma, Y.; Qiu, C.; Sun, T.; Liu, J.; Zhou, Q. Effect of graphene oxide nanosheets of microstructure and mechanical properties of cement composites. Constr. Build. Mater. 2013, 49, 121-127. [CrossRef]

26. Xu, G.; Du, S.; He, J.; Shi, X. The role of admixed graphene oxide in a cement hydration system. Carbon 2019, 148, 141-150. [CrossRef]

27. Horszczaruk, E.; Mijowska, E.; Kalenczuk, R.J.; Aleksandrzak, M.; Mijowska, S. Nanocomposite of cement/graphene oxideImpact on hydration kinetics and Young's modulus. Constr. Build. Mater. 2015, 78, 234-242. [CrossRef]

28. Qureshi, T.S.; Panesar, D.K. A review: The effect of graphene oxide on the properties of cement-based composites. In Proceedings of the CSCE Annual Conference, Vancouver, BC, Canada, 31 May-3 June 2017; p. 642-1.

29. Pan, Z.; He, L.; Qiu, L.; Korayem, A.H.; Li, G.; Zhu, J.W.; Collins, F.; Li, D.; Duan, W.H.; Wang, M.C. Mechanical properties and microstructure of a graphene oxide-cement composite. Cem. Concr. Compos. 2015, 58, 140-147. [CrossRef]

30. Najafi, F.; Wang, G.; Mukherjee, S.; Cui, T.; Filleter, T.; Singh, C.V. Toughening of graphene-based polymer nanocomposites via tuning chemical functionalization. Compos. Sci. Technol. 2020, 194, 108140. [CrossRef]

31. Cao, C.; Daly, M.; Singh, C.V.; Sun, Y.; Filleter, T. High strength measurement of monolayer graphene oxide. Carbon 2015, 81, 497-504. [CrossRef]

32. Kauling, A.P.; Seefeldt, A.T.; Pisoni, D.P.; Pradeep, R.C.; Bentini, R.; Oliveira, R.V.B.; Novoselov, K.S.; Castro Neto, A.H. The worldwide graphene flake production. Adv. Mater. 2018, 30, e1803784. [CrossRef]

33. Boggild, P. The war on fake graphene. Nature 2018, 562, 502-503. [CrossRef]

34. Lowe, S.E.; Zhong, Y.L. Challenges of Industrial-Scale Graphene Oxide Production; Wiley Online Library: Hoboken, NJ, USA, 2017; pp. $410-431$.

35. Shamsaei, E.; de Souza, F.B.; Yao, X.; Benhelal, E.; Akbari, A.; Duan, W. Graphene-based nanosheets for stronger and more durable concrete: A review. Constr. Build. Mater. 2018, 183, 642-660. [CrossRef]

36. Yao, X.; Shamsaei, E.; Chen, S.; Zhang, Q.H.; de Souza, F.B.; Sagoe-Crentsil, K.; Duan, W. Graphene oxide-coated Poly(vinyl alcohol) fibers for enhanced fiber-reinforced cementitious composites. Compos. B Eng. 2019, 174, 107010. [CrossRef]

37. Chen, J.; Zhao, D.; Ge, H.; Wang, J. Graphene oxide-deposited carbon fiber/cement composites for electromagnetic interference shielding application. Constr. Build. Mater. 2015, 84, 66-72. [CrossRef]

38. Lu, Z.; Hanif, A.; Sun, G.; Liang, R.; Parthasarathy, P.; Li, Z. Highly dispersed graphene oxide electrodeposited carbon fiber reinforced cement-based materials with enhanced mechanical properties. Cem. Concr. Compos. 2018, 87, 220-228. [CrossRef]

39. Yao, X.; Shamsaei, E.; Wang, W.; Zhang, S.; Sagoe-Crentsil, K.; Duan, W. Graphene-based modification on the interface in fibre reinforced cementitious composites for improving both strength and toughness. Carbon 2020, 170, 493-502. [CrossRef]

40. Lu, Z.; Yu, J.; Yao, J.; Hou, D. Experimental and molecular modeling of polyethylene fiber/cement interface strengthened by graphene oxide. Cem. Concr. Compos. 2020, 112, 103676. [CrossRef]

41. Chen, Z.-S.; Zhou, X.; Wang, X.; Guo, P. Mechanical behavior of multilayer GO carbon-fiber cement composites. Constr. Build. Mater. 2018, 159, 205-212. [CrossRef]

42. Jiang, W.; Li, X.; Lv, Y.; Zhou, M.; Liu, Z.; Ren, Z.; Yu, Z. Cement-Based Materials Containing Graphene Oxide and Polyvinyl Alcohol Fiber: Mechanical Properties, Durability, and Microstructure. Nanomaterials 2018, 8, 638. [CrossRef]

43. Richardson, J.J.; Bjornmalm, M.; Caruso, F. Technology-driven layer-by-layer assembly of nanofilms. Science 2015, 348 , aaa2491. [CrossRef] [PubMed]

44. Gadakh, D.; Dashora, P.; Wadhankar, G. A Review Paper on Graphene Coated Fibres. Graphene 2019, 8, 53-74. [CrossRef]

45. Zhang, Y.; Shen, Q.; Hou, J.; Sutrisna, P.D.; Chen, V. Shear-aligned graphene oxide laminate/Pebax ultrathin composite hollow fiber membranes using a facile dip-coating approach. J. Mater. Chem. A 2017, 5, 7732-7737. [CrossRef]

46. Gong, K.; Pan, Z.; Korayem, A.H.; Qiu, L.; Li, D.; Collins, F.; Wang, C.M.; Duan, W.H. Reinforcing effects of graphene oxide on portland cement paste. J. Mater. Civ. Eng. 2015, 27, A4014010. [CrossRef]

47. Li, W.; Li, X.; Chen, S.J.; Liu, Y.M.; Duan, W.H.; Shah, S.P. Effects of graphene oxide on early-age hydration and electrical resistivity of Portland cement paste. Constr. Build. Mater. 2017, 136, 506-514. [CrossRef]

48. Lu, Z.; Li, X.; Hanif, A.; Chen, B.; Parthasarathy, P.; Yu, J.; Li, Z. Early-age interaction mechanism between the graphene oxide and cement hydrates. Constr. Build. Mater. 2017, 152, 232-239. [CrossRef]

49. Qureshi, T.S.; Panesar, D.K.; Sidhureddy, B.; Chen, A.; Wood, P.C. Nano-cement composite with graphene oxide produced from epigenetic graphite deposit. Compos. B Eng. 2019, 159, 248-258. [CrossRef]

50. Han, B.; Zhang, L.; Zeng, S.; Dong, S.; Yu, X.; Yang, R.; Ou, J. Nano-core effect in nano-engineered cementitious composites. Compos. A Appl. Sci. Manuf. 2017, 95, 100-109. [CrossRef]

51. Taylor, H.F. Cement Chemistry; Thomas Telford London: London, UK, 1997; Volume 2.

52. Constantinides, G.; Ulm, F.-J. The nanogranular nature of C-S-H. J. Mech. Phys. Solids 2007, 55, 64-90. [CrossRef]

53. Gaitero, J.J.; Campillo, I.; Guerrero, A. Reduction of the calcium leaching rate of cement paste by addition of silica nanoparticles. Cem. Concr. Res. 2008, 38, 1112-1118. [CrossRef]

54. Qureshi, T.S.; Panesar, D.K. Impact of graphene oxide and highly reduced graphene oxide on cement based composites. Constr. Build. Mater. 2019, 206, 71-83. [CrossRef] 
55. Du, H.; Dai Pang, S. Enhancement of barrier properties of cement mortar with graphene nanoplatelet. Cem. Concr. Res. 2015, 76, 10-19. [CrossRef]

56. Murugan, M.; Santhanam, M.; Gupta, S.S.; Pradeep, T.; Shah, S.P. Influence of 2D rGO nanosheets on the properties of OPC paste. Cem. Concr. Compos. 2016, 70, 48-59. [CrossRef]

57. Lu, Z.; Hou, D.; Ma, H.; Fan, T.; Li, Z. Effects of graphene oxide on the properties and microstructures of the magnesium potassium phosphate cement paste. Constr. Build. Mater. 2016, 119, 107-112. [CrossRef]

58. Zhao, Y.; Liu, Y.; Shi, T.; Gu, Y.; Zheng, B.; Zhang, K.; Xu, J.; Fu, Y.; Shi, S. Study of mechanical properties and early-stage deformation properties of graphene-modified cement-based materials. Constr. Build. Mater. 2020, 257, 119498. [CrossRef]

59. Wan, H.; Zhang, Y. Interfacial bonding between graphene oxide and calcium silicate hydrate gel of ultra-high performance concrete. Mater. Struct. 2020, 53, 1-12. [CrossRef]

60. Wang, P.; Qiao, G.; Guo, Y.; Zhang, Y.; Hou, D.; Jin, Z.; Zhang, J.; Wang, M.; Hu, X. Molecular dynamics simulation of the interfacial bonding properties between graphene oxide and calcium silicate hydrate. Constr. Build. Mater. 2020, $260,119927$. [CrossRef]

61. Kai, M.F.; Zhang, L.W.; Liew, K.M. Graphene and graphene oxide in calcium silicate hydrates: Chemical reactions, mechanical behavior and interfacial sliding. Carbon 2019, 146, 181-193. [CrossRef]

62. Chen, S.J.; Li, C.Y.; Wang, Q.; Duan, W.H. Reinforcing mechanism of graphene at atomic level: Friction, crack surface adhesion and 2D geometry. Carbon 2017, 114, 557-565. [CrossRef]

63. Wang, G.; Liu, L.; Zhang, Z. Interface mechanics in carbon nanomaterials-based nanocomposites. Compos. A Appl. Sci. Manuf. 2021, 141, 106212. [CrossRef]

64. Liu, C.; Huang, X.; Wu, Y.-Y.; Deng, X.; Liu, J.; Zheng, Z.; Hui, D. Review on the research progress of cement-based and geopolymer materials modified by graphene and graphene oxide. Nanotechnol. Rev. 2020, 9, 155-169. [CrossRef]

65. Zheng, Q.; Han, B.; Cui, X.; Yu, X.; Ou, J. Graphene-engineered cementitious composites: Small makes a big impact. Nanomater. Nanotechnol. 2017, 7, 184798041774230. [CrossRef]

66. Long, W.-J.; Li, H.-D.; Fang, C.-L.; Xing, F. Uniformly dispersed and re-agglomerated graphene oxide-based cement pastes: A comparison of rheological properties, mechanical properties and microstructure. Nanomaterials 2018, 8, 31. [CrossRef]

67. Wang, B.; Jiang, R.; Wu, Z. Investigation of the mechanical properties and microstructure of graphene nanoplatelet-cement composite. Nanomaterials 2016, 6, 200. [CrossRef]

68. Lin, Z.; Kanda, T.; Li, V.C. On interface property characterization and performance of fiber reinforced cementitious composites. Concr. Sci. Eng. 1999, 1, 173-174.

69. Stang, H.; Li, V.C.; Krenchel, H. Design and structural applications of stress-crack width relations in fibre reinforced concrete. Mater. Struct. 1995, 28, 210-219. [CrossRef]

70. Chou, C.T.; Gaur, U.; Miller, B. Fracture Mechanisms during Fiber Pull-out for Carbon-Fiber-Reinforced Thermosetting Composites. Compos. Sci. Technol. 1993, 48, 307-316. [CrossRef]

71. Chua, P.; Piggott, M. The glass fibre-Polymer interface: I-Theoretical consideration for single fibre pull-out tests. Compos. Sci. Technol. 1985, 22, 33-42. [CrossRef]

72. Daly, M.; Cao, C.; Sun, H.; Sun, Y.; Filleter, T.; Singh, C.V. Interfacial shear strength of multilayer graphene oxide films. ACS Nano 2016, 10, 1939-1947. [CrossRef] [PubMed]

73. Cao, C.; Daly, M.; Chen, B.; Howe, J.Y.; Singh, C.V.; Filleter, T.; Sun, Y. Strengthening in Graphene Oxide Nanosheets: Bridging the Gap between Interplanar and Intraplanar Fracture. Nano Lett. 2015, 15, 6528-6534. [CrossRef]

74. Jancar, J. Review of the role of the interphase in the control of composite performance on micro- and nano-length scales. J. Mater. Sci. 2008, 43, 6747-6757. [CrossRef]

75. Kong, W.; Kum, H.; Bae, S.H.; Shim, J.; Kim, H.; Kong, L.; Meng, Y.; Wang, K.; Kim, C.; Kim, J. Path towards graphene commercialization from lab to market. Nat. Nanotechnol. 2019, 14, 927-938. [CrossRef]

76. Wang, G.; Dai, Z.; Liu, L.; Hu, H.; Dai, Q.; Zhang, Z. Tuning the interfacial mechanical behaviors of monolayer graphene/PMMA nanocomposites. ACS Appl. Mater. Interfaces 2016, 8, 22554-22562. [CrossRef]

77. Yang, H.; Cui, H.; Tang, W.; Li, Z.; Han, N.; Xing, F. A critical review on research progress of graphene/cement based composites. Compos. A Appl. Sci. Manuf. 2017, 102, 273-296. [CrossRef]

78. Lin, Y.; Du, H. Graphene reinforced cement composites: A review. Constr. Build. Mater. 2020, 265, 120312. [CrossRef]

79. Chuah, S.; Pan, Z.; Sanjayan, J.G.; Wang, C.M.; Duan, W.H. Nano reinforced cement and concrete composites and new perspective from graphene oxide. Constr. Build. Mater. 2014, 73, 113-124. [CrossRef]

80. Zhou, G.X.; Li, C.; Zhao, Z.; Qi, Y.Z.; Yang, Z.H.; Jia, D.C.; Zhong, J.; Zhou, Y. 3D printing geopolymer nanocomposites: Graphene oxide size effects on a reactive matrix. Carbon 2020, 164, 215-223. [CrossRef]

81. Korniejenko, K.; Lin, W.T.; Šimonová, H. Mechanical properties of short polymer fiber-reinforced geopolymer composites. J. Compos. Sci. 2020, 4, 128. [CrossRef]

82. Ranjbar, N.; Mehrali, M.; Mehrali, M.; Alengaram, U.J.; Jumaat, M.Z. Graphene nanoplatelet-fly ash based geopolymer composites. Cem. Concr. Res. 2015, 76, 222-231. [CrossRef]

83. Zhong, J.; Zhou, G.X.; He, P.G.; Yang, Z.H.; Jia, D.C. 3D printing strong and conductive geo-polymer nanocomposite structures modified by graphene oxide. Carbon 2017, 117, 421-426. [CrossRef] 
84. Xu, J.; Zhang, D. Multifunctional structural supercapacitor based on graphene and geopolymer. Electrochim. Acta 2017, 224, 105-112. [CrossRef]

85. Mehta, P.K.; Monteiro, P.J. Concrete: Microstructure, Properties, and Materials; McGraw-Hill Education: New York, NY, USA, 2014

86. Sanchez, F.; Sobolev, K. Nanotechnology in concrete-A review. Constr. Build. Mater. 2010, 24, 2060-2071. [CrossRef]

87. Aitcin, P.-C.; Neville, A.; Acker, P. Integrated view of shrinkage deformation. Concr. Int. 1997, 19, 35-41.

88. Zhang, P.; Li, Q.-F. Effect of polypropylene fiber on durability of concrete composite containing fly ash and silica fume. Compos. $B$ Eng. 2013, 45, 1587-1594. [CrossRef]

89. Madhavi, T.C.; Annamalai, S. Electrical conductivity of concrete. ARPN J. Eng. Appl. Sci. 2016, 11, 5979-5982.

90. Yoo, D.-Y.; You, I.; Lee, S.-J. Electrical properties of cement-based composites with carbon nanotubes, graphene, and graphite nanofibers. Sensors 2017, 17, 1064. [CrossRef]

91. Bai, S.; Jiang, L.; Jiang, Y.; Jin, M.; Jiang, S.; Tao, D. Research on electrical conductivity of graphene/cement composites. Adv. Cem. Res. 2020, 32, 45-52. [CrossRef]

92. Gopalakrishnan, R.; Kaveri, R. Using graphene oxide to improve the mechanical and electrical properties of fiber-reinforced high-volume sugarcane bagasse ash cement mortar. Eur. Phys. J. Plus 2021, 136, 1-15. [CrossRef]

93. Uygunoğlu, T.; Şimşek, B.; Ceran, Ö.B.; Eryeşil, Ö. Novel hybrid fiber reinforced mortar production using polyvinyl alcohol with a blend of graphene oxide and silver nanoparticles. J. Build. Eng. 2021, 44, 102641. [CrossRef]

94. Wanasinghe, D.; Aslani, F.; Ma, G.; Habibi, D. Advancements in electromagnetic interference shielding cementitious composites. Constr. Build. Mater. 2020, 231, 117116. [CrossRef]

95. Singh, A.P.; Mishra, M.; Chandra, A.; Dhawan, S. Graphene oxide/ferrofluid/cement composites for electromagnetic interference shielding application. Nanotechnology 2011, 22, 465701. [CrossRef]

96. Long, W.-J.; Gu, Y.-C.; Ma, H.; Li, H.-D.; Xing, F. Mitigating the electromagnetic radiation by coupling use of waste cathode-ray tube glass and graphene oxide on cement composites. Compos. B Eng. 2019, 168, 25-33. [CrossRef]

97. Zhao, D.; Chen, J.; Gao, Q.; Ge, H.Y. Graphene oxide/cement composites for electromagnetic interference shielding. In Materials Science Forum; Trans Tech Publications: Stafa-Zurich, Switzerland, 2015; pp. 485-489.

98. Zukowski, B.; dos Santos Mendonça, Y.G.; de Souza, J.V.B.; Toledo Filho, R.D. Cement-based EMI shielding materials. In Materials for Potential EMI Shielding Applications; Elsevier: Amsterdam, The Netherlands, 2020; pp. 333-340.

99. Weng, C.; Wang, G.; Dai, Z.; Pei, Y.; Liu, L.; Zhang, Z. Buckled AgNW/MXene hybrid hierarchical sponges for high-performance electromagnetic interference shielding. Nanoscale 2019, 11, 22804-22812. [CrossRef] [PubMed]

100. Weng, C.; Dai, Z.; Wang, G.; Liu, L.; Zhang, Z. Elastomer-Free, Stretchable, and Conformable Silver Nanowire Conductors Enabled by Three-Dimensional Buckled Microstructures. ACS Appl. Mater. Interfaces 2019, 11, 6541-6549. [CrossRef] [PubMed]

101. Che, R.C.; Peng, L.M.; Duan, X.F.; Chen, Q.; Liang, X.L. Microwave absorption enhancement and complex permittivity and permeability of Fe encapsulated within carbon nanotubes. Adv. Mater. 2004, 16, 401-405. [CrossRef]

102. Paredes, J.; Villar-Rodil, S.; Martínez-Alonso, A.; Tascon, J. Graphene oxide dispersions in organic solvents. Langmuir 2008, 24, 10560-10564. [CrossRef] [PubMed]

103. Simon, R.M. EMI shielding through conductive plastics. Polym. Plast. Technol. Eng. 1981, 17, 1-10. [CrossRef]

104. Song, W.-L.; Cao, M.-S.; Qiao, B.-B.; Hou, Z.-L.; Lu, M.-M.; Wang, C.-Y.; Yuan, J.; Liu, D.-N.; Fan, L.-Z. Nano-scale and micron-scale manganese dioxide vs corresponding paraffin composites for electromagnetic interference shielding and microwave absorption. Mater. Res. Bull. 2014, 51, 277-286. [CrossRef] 